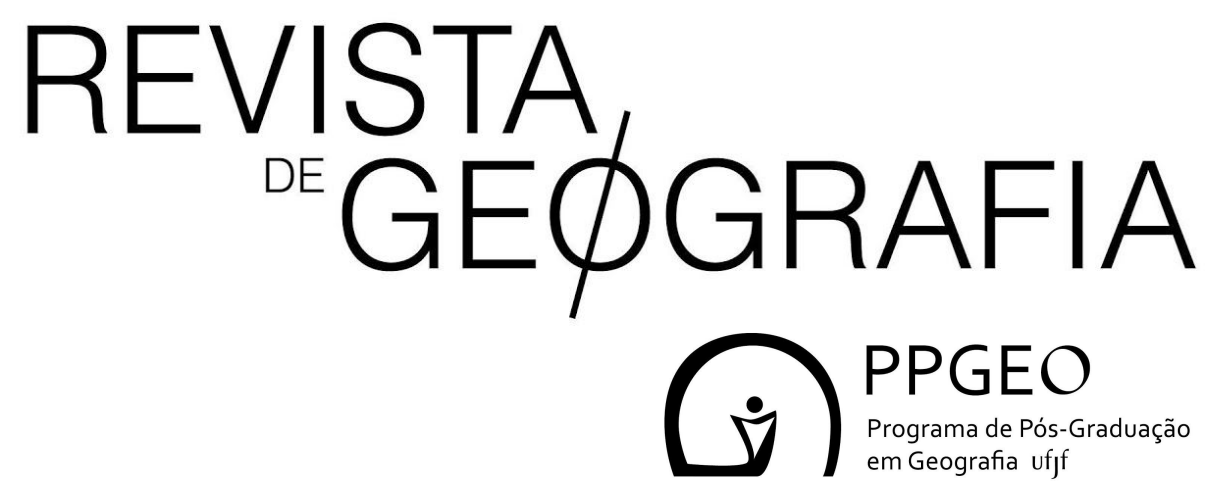

ISSN: 2236-837X

V. 9, n. 1,2019

\title{
PERCEPÇÃO DE RISCO CLIMÁTICO: UMA ANÁLISE PARA A CIDADE DE PORTO-PORTUGAL JUIZ DE FORA-BRASIL
}

Cássia de Castro Martins Ferreira Universidade Federal de Juiz de Fora/Universidade do Porto Av. José Lourenço Kelmer, S/N, Campus Universitário Bairro Martelos, CEP.: 36036-900, Juiz de Fora-MG E-mail: Cassia.castro@ufji.edu.br

Ana Monteiro Universidade do Porto Departamento de Geografia, Universidade do Porto/CEGOT Via Panorâmica s/n, 4150-564 Porto, Portugal E-mail: anamonteirosousa@gmail.com

Helena Madureira Universidade do Porto Departamento de Geografia, Universidade do Porto/CEGOT Via Panorâmica s/n, 4150-564 Porto, Portugal E-mail: hmadureiramail@gmail.com 


\section{Resumo}

Este estudo consiste na análise comparativa da percepção do risco climático, frente as alterações climáticas da população da Área Metropolitana de Porto-Pt e da cidade de Juiz de Fora-MG-Br. Para isso foi adotada uma metodologia participativa, por meio de um inquérito, envolvendo indivíduos residentes de ambas localidades e pesquisadores, que registraram as percepções, identificaram os maiores riscos e verificaram aonde os indivíduos mais participariam nas ações mitigadoras. Portanto, este estudo permitiu mostrar as percepções dos riscos climáticos em duas localidades com contextos sociais, políticos e econômicos distintos, porém, as respostas aos inquéritos foram similares em ambas as localidades.

Palavras Chaves: Alterações climáticas, adaptação as alterações climáticas, participação popular

\section{Abstract}

This study consists of a comparative analysis of the perception of climatic risk, in face of the climatic changes of the population in metropolitan area of the city of Porto - Pt and in the city of Juiz de Fora MG - Br. A participatory methodology was adopted through a survey involving individuals from both locations and researchers, who recorded the perceptions, identified the greatest risks and verified where the individuals would most participate in the mitigating actions. Therefore, this study allowed to show perceptions of climate risks in two localities with distinct social, political and economic contexts, but responses to surveys were similar in both locations.

Keywords: climate change, adaptation to climate change, popular participation 


\section{Introdução}

Não é incomum assistirmos à danos e perdas provocadas pelo aumento da desregulação climática local, regional e zonal, e pelo expressivo aumento de episódios climáticos extremos (MONTEIRO et al., 2012).

Estes danos e perdas quando olhados na escala urbana, toma uma dimensão expressiva, em função da crescente concentração populacional, o que desencadeia uma maior probabilidade de ocorrência de novos riscos e vulnerabilidades associadas às Alterações Climáticas e consequentemente novos desafios na governança das cidades se impõem.

Logo, as cidades tomam uma função primordial, pois nelas se encontram importantes fontes emissoras/poluentes, desta forma, um local importante no que tange a inclusão e adesão de programas de controle e redução das emissões/poluentes, quanto da necessidade de se adaptar às novas condições climáticas. Este fato é levantado pelo Programa das Nações Unidas para Habitação Humana (ONU-Habitat, 2011), pelo IPCC que destacou à questão urbana no seu $5^{\circ}$ e último relatório, no qual foram tratados temas como impactos, vulnerabilidade e adaptação às alterações do clima (IPCC, 2014; REVI et al., 2014, KLUG et al. 2016), além do 40 Turn Down the Heat: climate extremes, regional impacts, and the case for resilience (BANCO MUNDIAL, 2013).

Monteiro et al. (2012, p. 100) afirma que "a grande concentração de solo impermeabilizado e a variedade de usos a que este serve de suporte, sobretudo no Porto e nos concelhos próximos que corporizam a habitualmente designada coroa metropolitana portuense, geram alterações no balanço energético que modificam substantivamente o sistema climático local e regional".

Enquanto o IPCC, em suas projeções e cenários mais pessimistas estimam um aumento da temperatura do ar no globo em torno de $2,6^{\circ}$ a $4,8^{\circ} \mathrm{C}$ ao longo do século XXI, destacamos que estes acréscimos de temperaturas já vêm sendo vivenciados, registrados e estudados nas áreas urbanas, principalmente nas grandes e médias cidades, em várias localidades do globo (MONTEIRO et al., 2012; FIALHO, 2012; SOUSA et al., 2011; AMORIM et al., 2009; OKE, 1987; OKE, 1984). Fenômeno esse propiciado pelos "excedentes energéticos drenados por todas as atividades antrópicas habitualmente existentes em espaços urbanizados, acumulam-se com os aprisionamentos de energia sob a copa urbana provocados pela ausência de sumidouros naturais (vegetação, mosaicos de 
água, solo permeável a céu aberto, etc) para originar anomalias térmicas positivas muito elevadas, as ilhas de calor urbano" (MONTEIRO, et al., 2012, p. 101).

Desta forma, as alterações climáticas locais já são uma realidade e provocam uma série de riscos à população, a esses devem ser somadas as mudanças globais que poderá gerar um agravamento nos eventos extremos (MONTEIRO et al., 2012; SATHLER, 2014; IPCC, 2014).

Portanto, as cidades são o locus de duas questões centrais: a mitigação que envolve o controle e atividades que visam reduzir as emissões de gases estufa ou aumentar a fixação de $\mathrm{CO}_{2}$, integrando ações de vários setores (energia, indústria, construção, transporte, agricultura, reflorestamento e resíduos), além de uma adequação na estrutura, na morfologia e no processo de desenvolvimento urbano; e adaptação que significa ações, ou adequações visando a redução de impactes ou previsão de problemas advindos das alterações climáticas, antecipando consequências, minimizando danos e perdas e prospectando novas possibilidades. Os principais setores envolvidos nas políticas de adaptação são: recursos hídricos, agricultura, infraestrutura, saúde, turismo, transporte e energia (ADGER et al., 2003; BARBI e FERREIRA, 2013).

Pois, as cidades da mesma forma que são grandes contribuintes às Alterações Climáticas, são também os locais com maiores riscos e mais vulneráveis (WHILE e WHITEHEAD, 2013; SATHLER, 2014).

A literatura vem mostrando a ocorrência e a probabilidade de ocorrência futura de uma série de riscos climáticos, porém as ações e medidas ainda são incipientes em vários países, pois a ideia de que a ciência e a técnica são superiores à qualquer evento da natureza e que possíveis interações entre o homem e a atmosfera são insignificantes, indiferentemente da escala analisada, levam a uma falta ou pequena valorização de ações pertinentes à incorporação de projetos de mitigação, e daqueles voltados à adaptação as Alterações Climáticas (HOPPE e COENEN, 2014; ELIASSON, 2000; MONTEIRO e CARVALHO, 2013; MONTEIRO, 2013).

Desta forma, verifica-se uma série de cidades e governos locais empenhados na elaboração, de projetos, planos e programas que visam ações efetivas de mitigação e/ou de adaptação às alterações Climáticas (ClimAdaPT.Local: estratégias municipais de adaptação as alterações climáticas (PORTUGAL, 2015); National adaptation policy processes in European countries-2014 (EUROPEAN UNION, 2016); Climate change, impacts and vulnerability in Europe 2016 (EUROPEAN UNION, 2017a); An indicator-based report; Urban adaptation to climate change in Europe 2016 (EUROPEAN UNION, 2017b); $A$ stronger more resilient New York (NEW YORK, 2013); Paris Adaptation strategy: towards a more resilient 
city (PARIS, 2015); Climate change adaptation strategy: city os Vancouver (VANCOUVER, 2013); Helsinki Metropolitan Area Climate Change Adaptation Strategy (HELSINKI, 2012); Barcelona, a city committed to combating climate change (BARCELONA, 2013); Durban's Municipal Climate Protecon Programme: Climate change planning for resilient city, 2010/2011 (DURBAN, 2012); Manchester city council's climate change belivery plan 2010-2020 (MANCHESTER, 2011); Metro Boston Regional Climate Change Adaptation Strategy Report (BOSTON, 2014); Adreessing climate change risks, disasters, and adaptation in the People's Republic of China (ASIAN DEVELOPMENT BANK, 2015); Plano de adaptação da cidade do Rio de Janeiro as mudanças climáticas (RIO DE JANEIRO, 2017)). Outros tantos, sob a alegação de ainda estarem provendo serviços básicos (saúde, educação, saneamento, habitação, infraestrutura, etc) estão longe de desenvolverem políticas públicas eficazes para com as questões climáticas locais, o que leva a um quadro de potencialização do risco climático e consequentemente da vulnerabilidade futura dos impactes negativos das Alterações Climáticas, tornando portanto imprescindível que estes se preocupem com estas novas demandas.

Assim, a participação popular e o envolvimento da sociedade são peças importantes na definição e delineamento da percepção da sociedade quanto ao risco climático e à vulnerabilidade ambiental pela qual ela está exposta. O presente estudo objetiva conhecer como a população da Área Metropolitana do Porto-Portugal e da cidade de Juiz de Fora-Brasil percebem o risco climático, a vulnerabilidade a que ela estaria exposta aos impactos negativos das alterações Climáticas, os principais mecanismos de mitigação e adaptação nas cidades, a importância da escala nos estudos de Alterações climáticas, a governança, e o envolvimento pessoal e das comunidades nos projetos de mitigação e adaptação, como uma importante etapa na formação de um plano participativo de adaptação às alterações climáticas.

\section{Riscos Climáticos}

A ideia de que o conhecimento seria a chave para um maior ou mesmo total controle do homem sobre o ambiente e a natureza, perdurou até a humanidade se confrontar com riscos e perigos que estão longe do controle da ciência e, portanto, a grande evolução almejada pela humanidade foi despida, principalmente pelas alterações climáticas e provavelmente o aumento dos riscos socioambientais advindos delas. A complexidade do sistema e subsistemas climáticos impede uma intervenção humana nessa vertente, porém outras questões ficam emergentes, e dentre elas, perguntamos como administrar os riscos 
advindos das alterações climáticas.

Veyret (2007, p.12) define risco como “(..) a percepção de uma potencialidade de crise, de acidente ou de catástrofe, o que não é, portanto, o acontecimento catastrófico propriamente dito".

Se partimos do princípio que o conceito de risco é uma construção social, este também está relacionado à forma pelo qual a sociedade se organiza e vem se organizando num processo histórico, identificando por que camadas distintas da sociedade se encontram em condições de maior ou menor vulnerabilidade. Porém, é importante realçar que os riscos ambientais são segundo Veyret (2007, p. 63-64) a "associação entre os riscos decorrentes de processos naturais agravados pela atividade humana e pela ocupação do território". Sendo que os processos naturais seriam aqueles atrelados a deslizamentos, geologia, química dos gases, precipitação intensa, seca, etc. Para Castro (2000, p. 103) o risco ambiental é uma circunstância da existência social cuja natureza e significado dependem da experiência, do desenvolvimento socioeconômico e das estratégias com que se enfrentam os riscos.

Desta forma, risco não é igual a perigo, porém um pode conduzir ao outro. Não são iguais, por que o risco indica uma condição, que pode levar ao perigo num momento futuro (RAMIRES, 2015). A relação entre risco e desastre, também é de proximidade, pois o desastre é o resultado da exposição de cidadãos, prédios, vias de circulação, áreas protegidas, etc. ao risco, logo a magnitude do desastre dependerá do grau de vulnerabilidade que cada sociedade apresentará diante dos riscos (RAMIRES, 2015).

A maioria dos riscos apontados pelo IPCC (2014) são riscos já enfrentados nas áreas urbanas, como intensas chuvas, secas, enchentes, ondas de calor e frio, falta de água potável, movimentos de massa, etc). O que se ressalta, portanto, é a sua potencialização e consequentemente estes seriam mais frequentes e de maior magnitude. O que remete para uma crescente necessidade dos governos locais estarem cada vez mais preparados para os impactes das Alterações Climáticas. Pois, uma cidade na qual todas as habitações possuem boas condições de moradia, saneamento básico, infraestrutura, vias públicas, sistema de saúde enfim, elementos básicos de qualidade e acessíveis a toda a população, serão menos vulneráveis do que aquelas nas quais estes elementos são deficitários (FRIEND e MOENCH, 2013). Logo, uma cidade que investir na adaptação e conseguir atender a todas as necessidades básicas da sua população com qualidade estaria mais protegida do que aquelas que não o oferecem. Mesmo que saibamos que existe um enorme contingente de população urbana no mundo que está longe de ter os serviços urbanos básicos. 
Desta forma, Kowarick (2002) destaca que as cidades serão o locus das transformações ambientais mais significativas.

Uma das formas de verificar como a população percebe o risco climático, seria a de ampliação do debate, incluindo a participação pública, entendendo que as situações de risco é resultado de diferentes experiências empíricas, o que leva à necessidade de levar em consideração as percepções individuais e coletivas sobre os riscos que os indivíduos estão potencialmente expostos e integrar conhecimentos locais aos conhecimentos técnico-científicos (FREITAS, 2000; FUNTOWICZ e RAVETZ, 1997; RENN, 2008; DI GIULIO, 2012; DI GIULIO et al., 2012).

McCarney (2009) destaca que vários estudos sobre adaptação climática nas cidades, ainda consideram que a vulnerabilidade aos riscos climáticos, associados as alterações climáticas é subestimada. Pois, os problemas urbanos hoje já presentes são complexos e requerem uma análise integrada, quando associados as alterações climáticas ficam ainda mais complexos pois misturam questões locais com as de natureza global. Assim, Hardoy e Pandiella (2009) destacam que esta complexidade e os novos problemas ambientais serão mais impactantes para as populações que se encontram em condições maiores de vulnerabilidade.

\section{As manifestações de alterações climáticas na Área Metropolitana de Porto-Pt e da cidade de Juiz de Fora-Br}

A Área Metropolitana do Porto (AMP) possui um clima temperado mediterrâneo, influenciado pela posição geográfica e o sítio urbano, pelas diferenças altimétricas, pela concentração e fluxo de pessoas, além da intensidade e operação das atividades. Possui uma costa litorânea a oeste, no qual é banhado pelo Oceano Atlântico. A ocupação da área urbana foi sobre uma plataforma ligeiramente inclinada para o oceano Atlântico cujas altitudes variam entre os $160 \mathrm{~m}$ e o nível do mar. Localizada no Litoral Norte de Portugal, a AMP abarca uma área geográfica composta, por 17 municípios contíguos, numa área aproximada de $2.040 \mathrm{Km} 2$. Com uma população residente estimada em 1.700 .000 habitantes, é a segunda maior área metropolitana de Portugal (GAMP) (AMP, 2017) (Figura $1)$. 


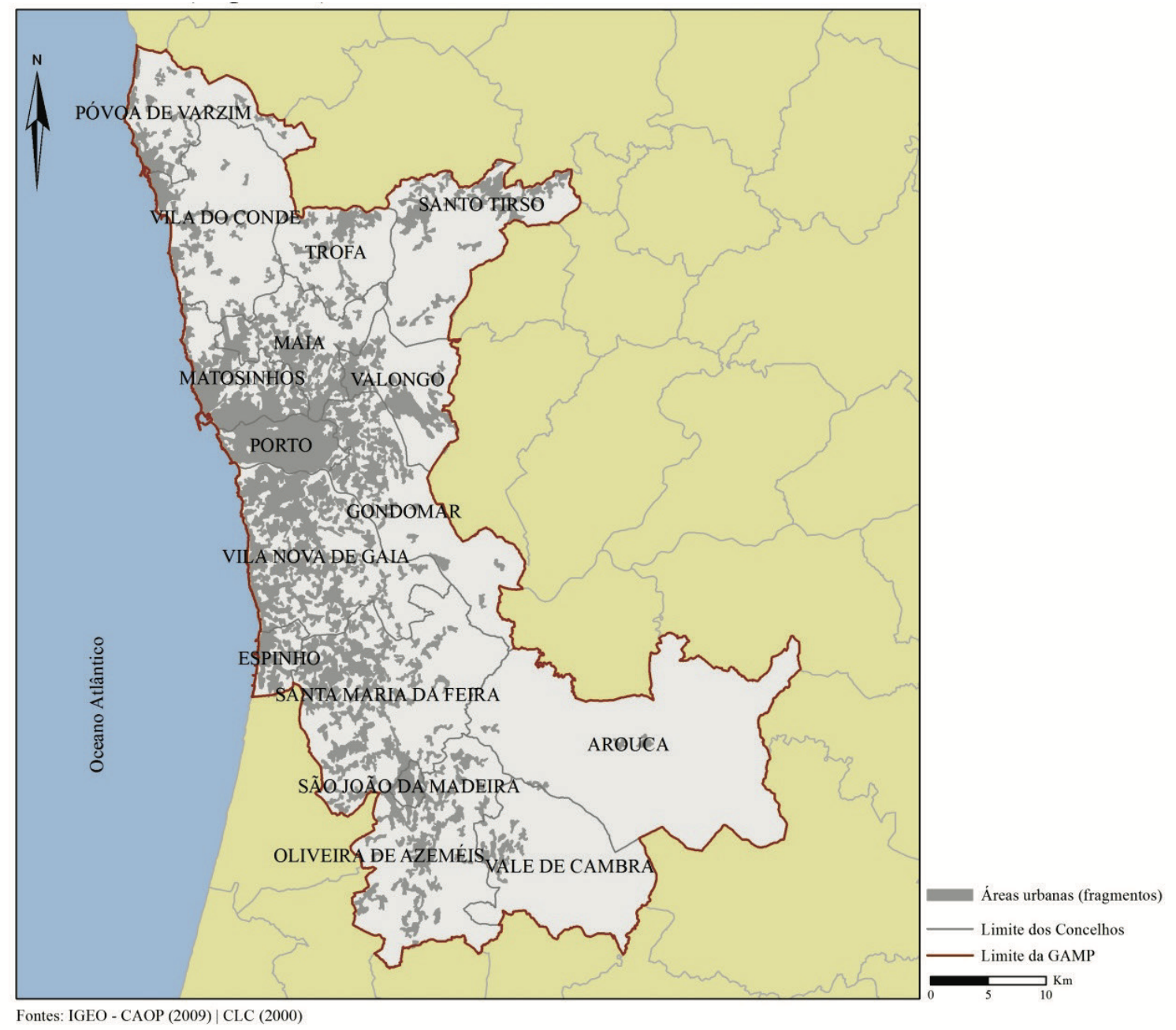

FIGURA 1: Localização da Área Metropolitana do Porto-Pt. Fonte: Monteiro, et al., 2012.

As relações, interações e interligações crescentes entre as atividades humanas no espaço e a baixa troposfera, são propiciadas cada vez mais pelas intensas alterações presentes no espaço urbano, tais como a impermeabilização do solo, a canalização dos cursos d'água, a fragmentação e eliminação dos espaços verdes, pelos efluentes emitidos, pela concentração da materialidade urbana, pela verticalização, pela intensidade do fluxo de veículos, ou seja, o volume de alterações no espaço urbana, produz, influencia e altera o sistema climático local e regional, para alguns autores também influenciam numa escala global (MONTEIRO et al. 2012, AMORIM et al., 2009, OKE, 1987).

Estas influencias foram detectadas quando analisada a série temporal da estação climatológica do Porto-Serra do Pilar, do período de 1880 - 2007, tendo-se verificado uma tendência de aumento da temperatura do ar (Figura 2), acompanhada de um maior número de dias com altas e baixas temperaturas (Figuras 3 e 4), uma alteração no regime das chuvas, assim como sua distribuição (Figura 5). Constatando portanto um aumento no 
número de eventos extremos, sejam eles de origem térmica ou hídrica.

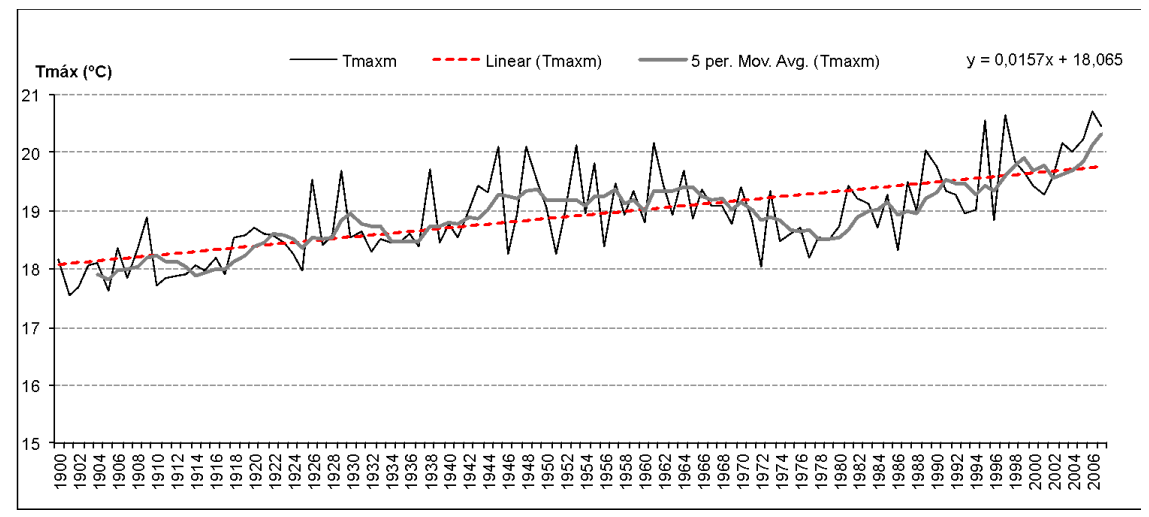

FIGURA 2: Médias móveis e tendência linear do comportamento da temperatura média mínima anual no Porto

Serra do Pilar (1900-2007). Fonte: Monteiro, et al., 2012

\section{QUADRO 1}

Sequências de dias com temperatura máxima $>31^{\circ} \mathrm{C}$ no Porto Serra do Pilar entre 1900 e 2007.

\begin{tabular}{|c|c|c|c|c|c|c|c|c|c|c|}
\hline \multicolumn{11}{|c|}{ Número de sequências de dias, por década, com temperatura máxima $\geq 31^{\circ} \mathrm{C}$} \\
\hline & 2 & 3 & 4 & 5 & 6 & 7 & 8 & $\mathbf{9}$ & 10 & Total \\
\hline $1901-1910$ & 9 & 2 & 1 & 0 & 0 & 0 & 0 & 0 & 0 & 12 \\
\hline 1911-1920 & 7 & 4 & 3 & 2 & 0 & 0 & 0 & 0 & 0 & 16 \\
\hline 1921-1930 & 11 & 9 & 5 & 0 & 1 & 1 & 0 & 0 & 0 & 27 \\
\hline $1931-1940$ & 11 & 5 & 1 & 4 & 0 & 0 & 0 & 0 & 0 & 21 \\
\hline $1941-1950$ & 21 & 8 & 3 & 1 & 1 & 0 & 0 & 0 & 0 & 34 \\
\hline $1951-1960$ & 7 & 5 & 3 & 1 & 0 & 0 & 0 & 0 & 0 & 16 \\
\hline $1961-1970$ & 16 & 10 & 5 & 0 & 2 & 0 & 0 & 0 & 0 & 33 \\
\hline $1971-1980$ & 13 & 3 & 2 & 1 & 0 & 0 & 0 & 0 & 0 & 19 \\
\hline $1981-1990$ & 13 & 9 & 5 & 3 & 0 & 0 & 1 & 0 & 0 & 31 \\
\hline 1991-2000 & 15 & 7 & 3 & 1 & 0 & 0 & 0 & 1 & 0 & 27 \\
\hline $2001-2007$ & 15 & 6 & 5 & 2 & 0 & 1 & 0 & 0 & 1 & 30 \\
\hline Total & 138 & 68 & 36 & 15 & 4 & 2 & 1 & 1 & 1 & 266 \\
\hline
\end{tabular}

Fonte: Monteiro et al., 2012.

QUADRO 2

Sequências de dias com temperatura mínima $<1^{\circ} \mathrm{C}$ no Porto Serra do Pilar entre 1900 e 2007.

\begin{tabular}{|c|c|c|c|c|c|c|c|c|c|c}
\hline \multicolumn{10}{|c}{ Número de sequências de dias, por década, com temperatura mínima $\leq \mathbf{1}^{\mathbf{0}} \mathbf{C}(\mathbf{P} \mathbf{)}$} \\
\hline & $\mathbf{2}$ & $\mathbf{3}$ & $\mathbf{4}$ & $\mathbf{5}$ & $\mathbf{6}$ & $\mathbf{7}$ & $\mathbf{8}$ & $\mathbf{9}$ & $\mathbf{1 0}$ & Total \\
\hline $1901-1910$ & 14 & 1 & 0 & 0 & 0 & $\mathbf{1}$ & 0 & 0 & 0 & 16 \\
\hline $1911-1920$ & 10 & 1 & 2 & 2 & 0 & 0 & 0 & 0 & 0 & 15 \\
\hline $1921-1930$ & 12 & 6 & 4 & 0 & 2 & 0 & 1 & 0 & 0 & 25 \\
\hline $1931-1940$ & 11 & $\mathbf{1 1}$ & 4 & $\mathbf{9}$ & $\mathbf{3}$ & $\mathbf{1}$ & 0 & 1 & 1 & 41 \\
\hline $1941-1950$ & 16 & 5 & 8 & 3 & 1 & 0 & 1 & 0 & 0 & 34 \\
\hline $1951-1960$ & 18 & 3 & 5 & 2 & 4 & 2 & 0 & 0 & 0 & 34 \\
\hline $1961-1970$ & 13 & 9 & 5 & 2 & 2 & 1 & 1 & 0 & 0 & 33 \\
\hline $1971-1980$ & 13 & 6 & 2 & 4 & 2 & 0 & 0 & 0 & 0 & 27 \\
\hline $1981-1990$ & 8 & 1 & 1 & 2 & 0 & 0 & 0 & 0 & 2 & 14 \\
\hline $1991-2000$ & 7 & 3 & 2 & 1 & 0 & 0 & 0 & 0 & 0 & 13 \\
\hline $2001-2007$ & 5 & 1 & 2 & 1 & 0 & 0 & 1 & 0 & 0 & 10 \\
\hline Total & $\mathbf{1 2 7}$ & $\mathbf{4 7}$ & $\mathbf{3 5}$ & $\mathbf{2 6}$ & $\mathbf{1 4}$ & $\mathbf{5}$ & $\mathbf{4}$ & $\mathbf{1}$ & $\mathbf{3}$ & $\mathbf{2 6 2}$
\end{tabular}

Fonte: Monteiro et al., 2012. 


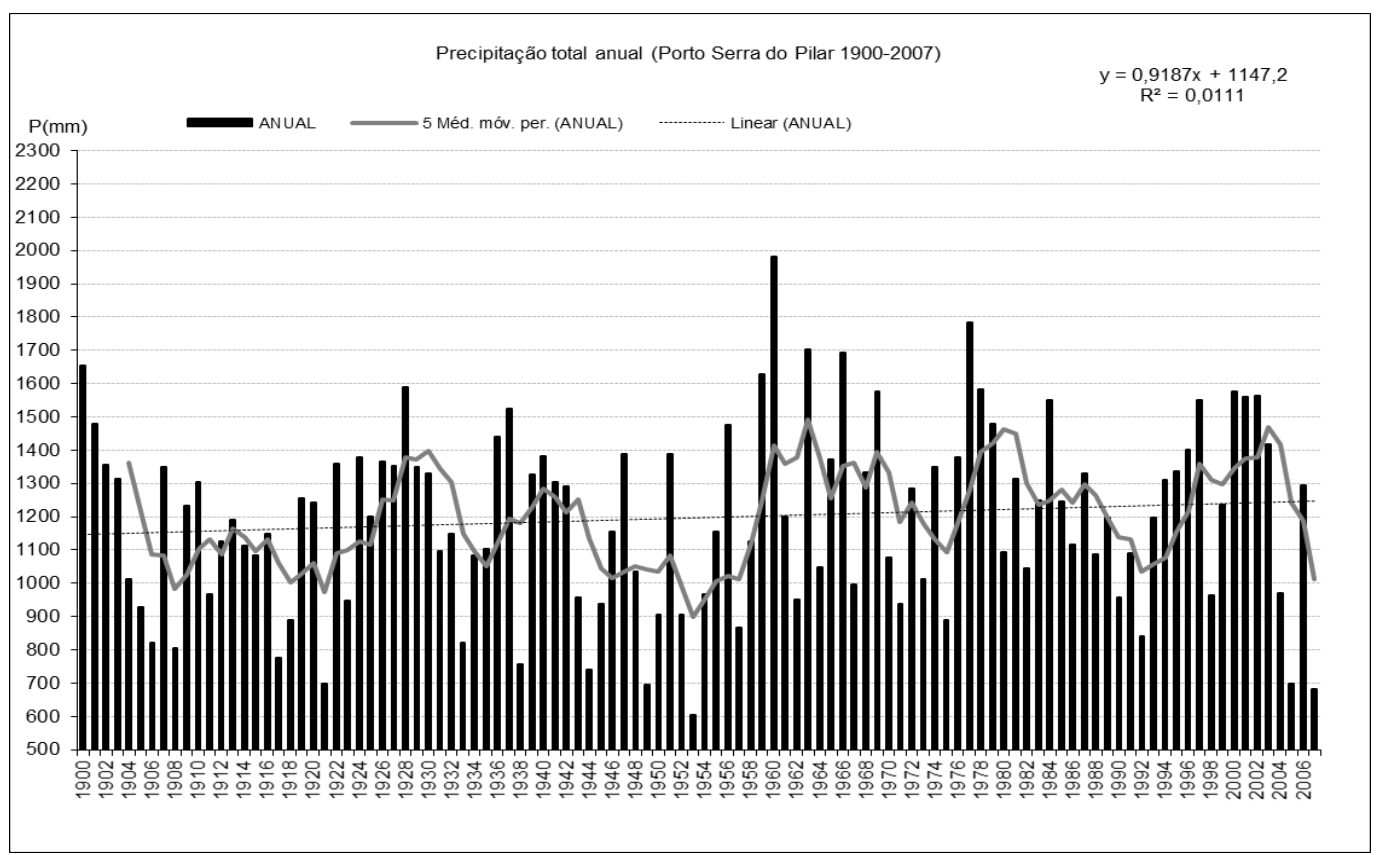

FIGURA 3 - Médias móveis e tendência linear do comportamento da precipitação anual no Porto Serra do Pilar entre 1900 e 2007. Fonte: Monteiro et al., 2012.

Juiz de Fora é uma cidade com uma população residente estimada de 563.769, sendo que destes $98,9 \%$ da população reside na área urbana e os demais 1,13\% na zona rural, o município compreende uma área de 1435,749 km² (IBGE, 2017). Está localizada na mesorregião da Zona da Mata do Estado de Minas Gerais, Brasil. A cidade é o principal polo regional, apresentando ampla gama de serviços e infraestruturas. Dessa forma, ao longo de sua história, tem passado por incessantes dinâmicas, com significativas alterações na sua estrutura, área, adensamento, resultantes do crescimento demográfico causado pelo seu crescimento vegetativo, e também do significativo fluxo migratório de cidades menores da região (Figura 2). 

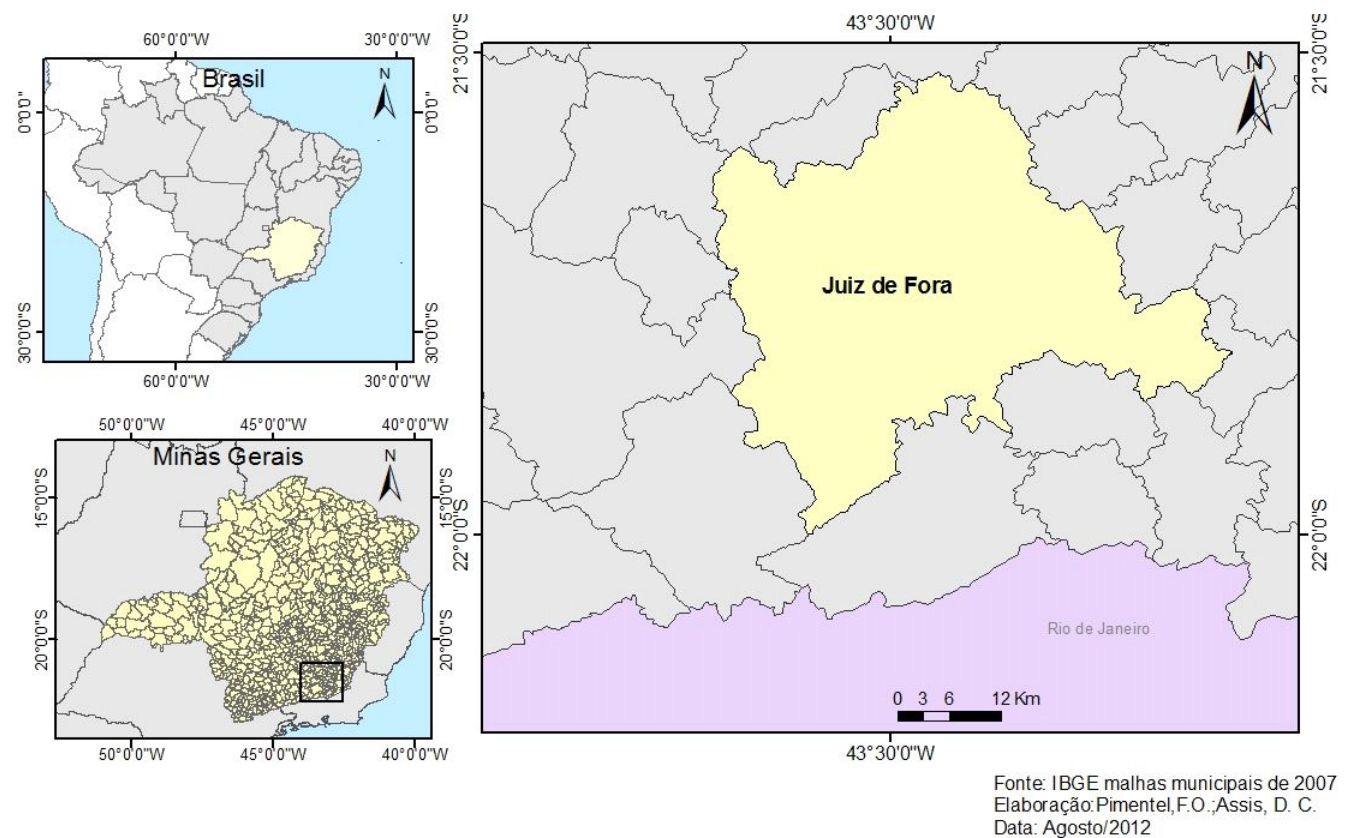

FIGURA 4- Localização do Município de Juiz de Fora-MG-Brasil. Fonte próprio autor 2017.

A cidade de Juiz de Fora está localizada numa zona de clima tropical de altitude, seu clima é derivado dos fatores geográficos e morfológicos, sendo também influenciado pelas interações do modo de ocupação urbana, com as significativas diferenças altimétricas encontradas no sítio urbano, atrelados aos processos de ocupação, adensamento populacional, supressão da cobertura vegetal, elevada verticalização do centro e subcentros urbanos, associados a um volume significativo da frota veicular, intensificando as trocas de calor e gases gerados na superfície com a atmosfera. A intensificação da transformação da paisagem urbana e da concentração populacional, gerou uma alteração no clima urbano, intensificando a temperatura do ar (Figura 5). Assim como no aumento do número de dias quentes e uma diminuição no número de dias com baixas temperaturas (Figuras 6 e 7). Apresenta uma variabilidade da precipitação mas com nenhuma tendência significativa (Figura 8). 


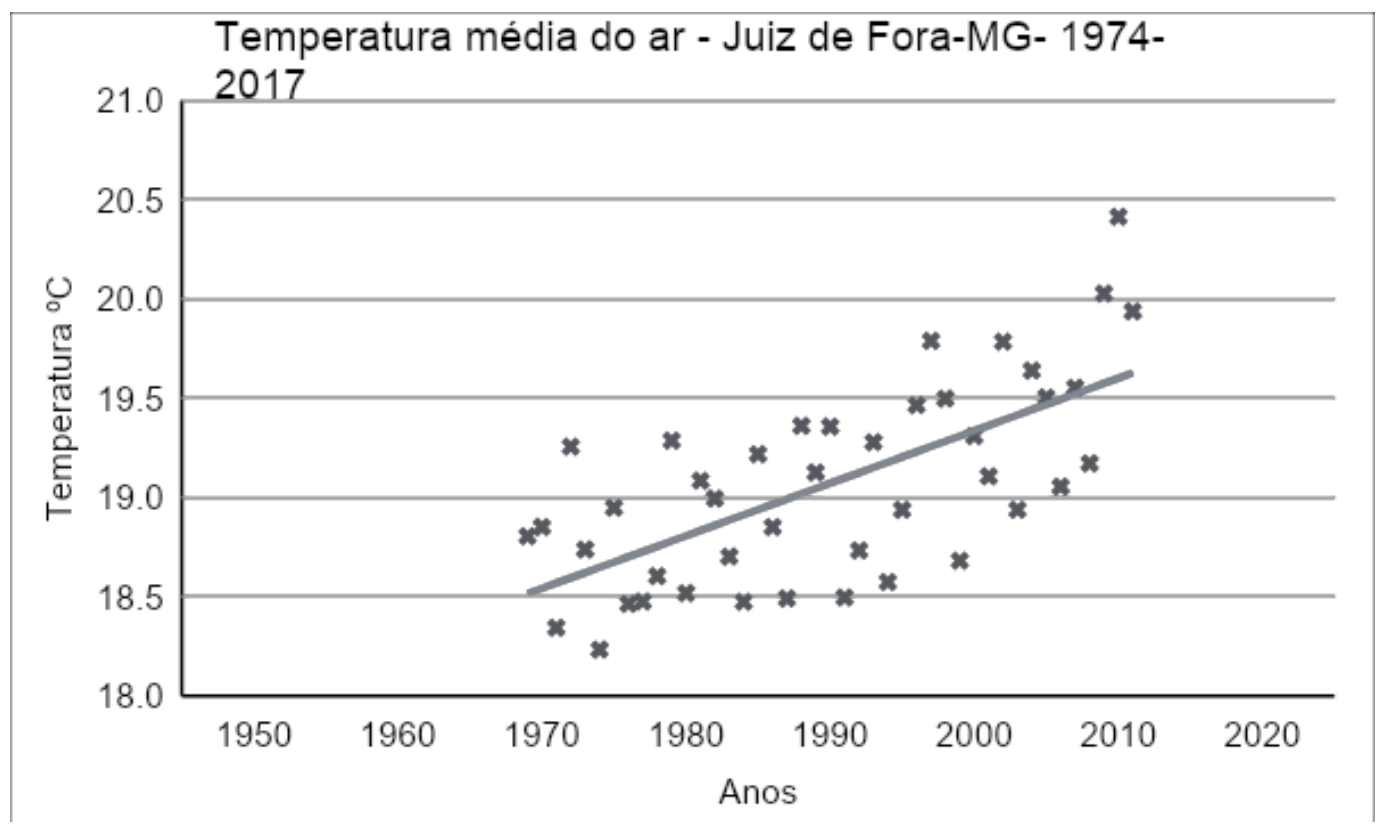

FIGURA 5: Médias móveis e tendência linear do comportamento da temperatura média anual em Juiz de Fora- $\mathrm{Br}$ (1974-2016). Fonte: próprio autor, 2018.

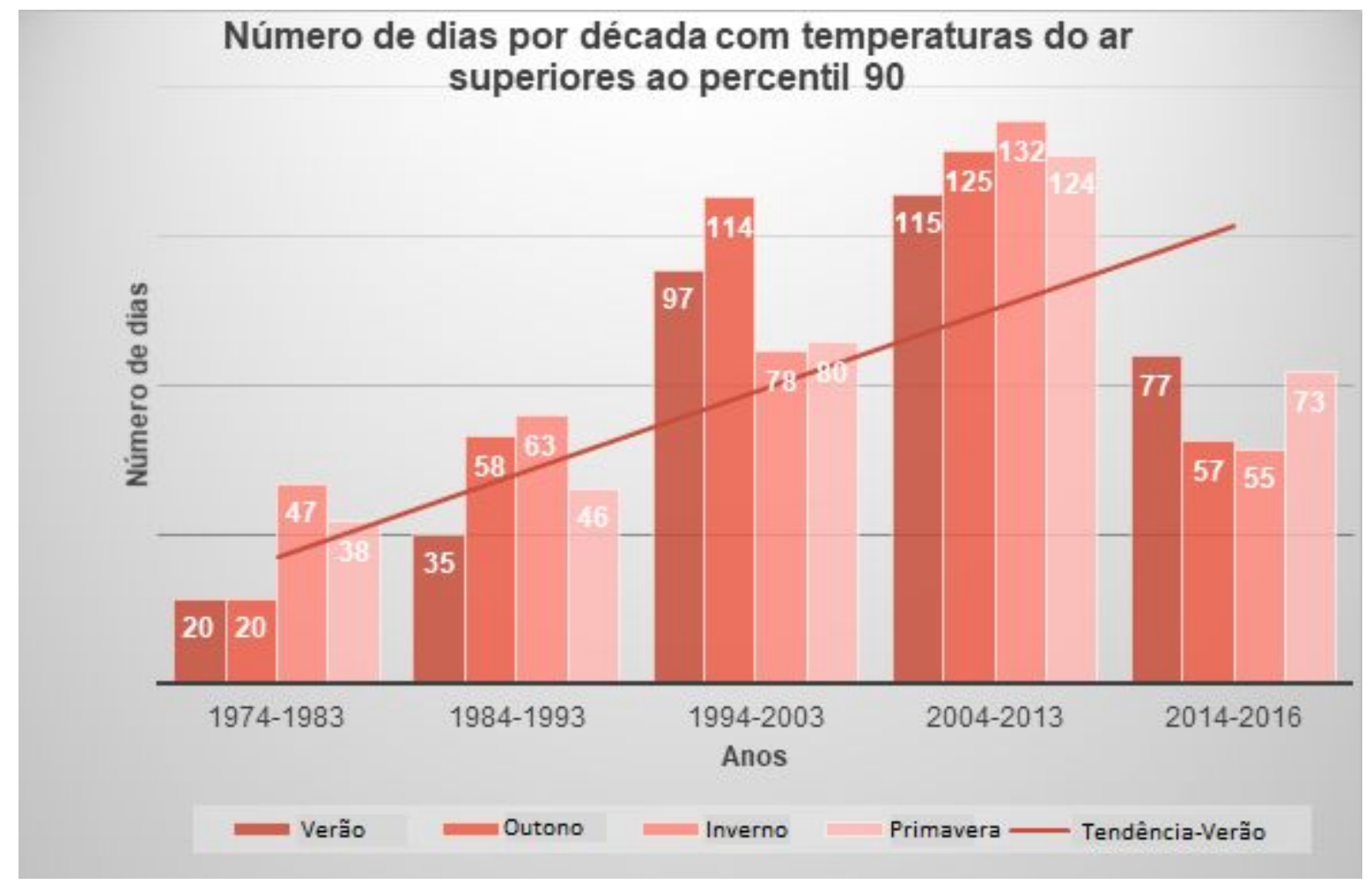

FIGURA 6: Número de dias por década, com temperatura do ar superior ao percentil 90 em Juiz de Fora-Br (1974-2016). Fonte: próprio autor, 2018. 


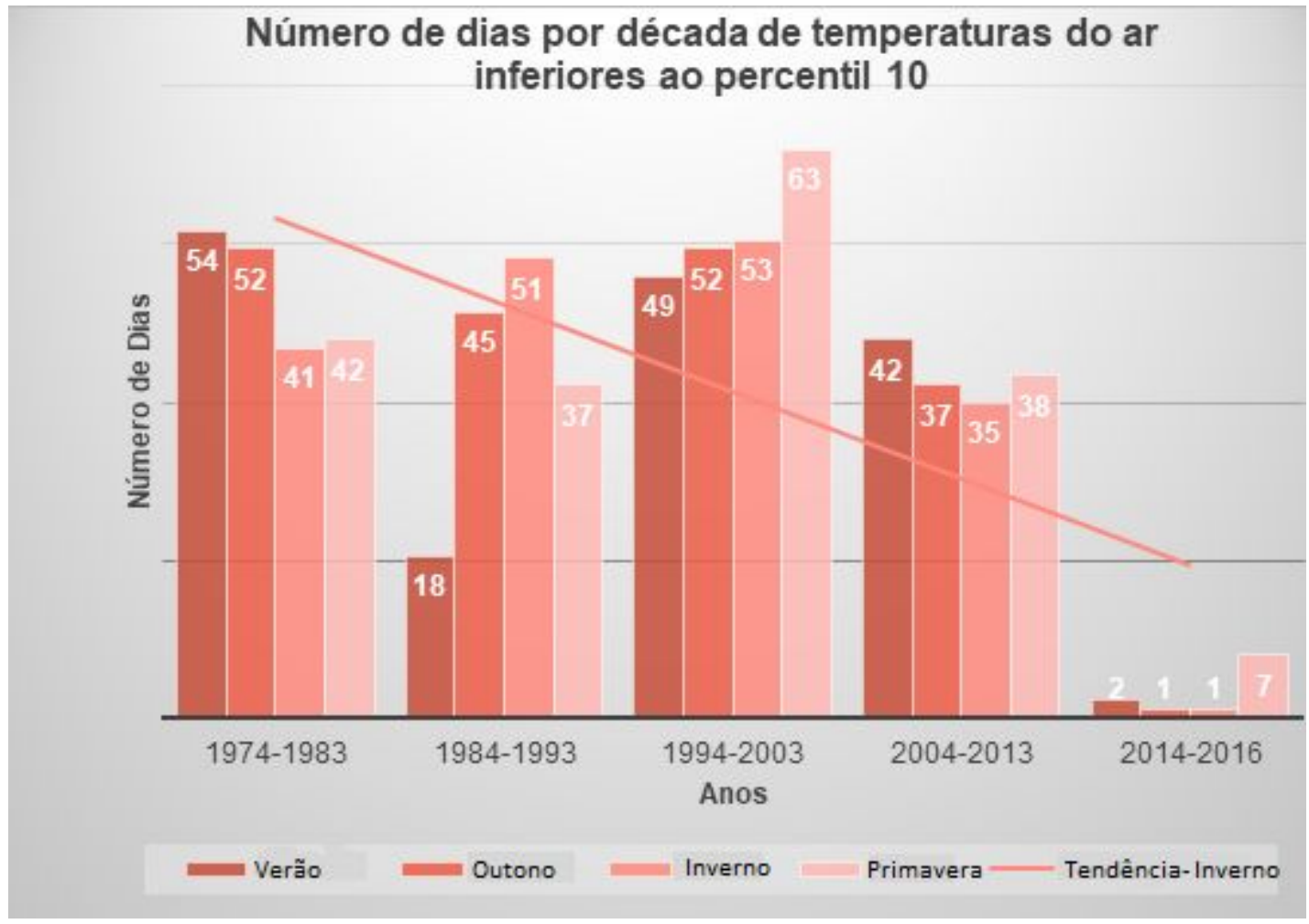

FIGURA 7: Número de dias por década, com temperatura do ar inferior ao percentil 10, em Juiz de Fora-Br (1974-2016). Fonte: próprio autor, 2018.

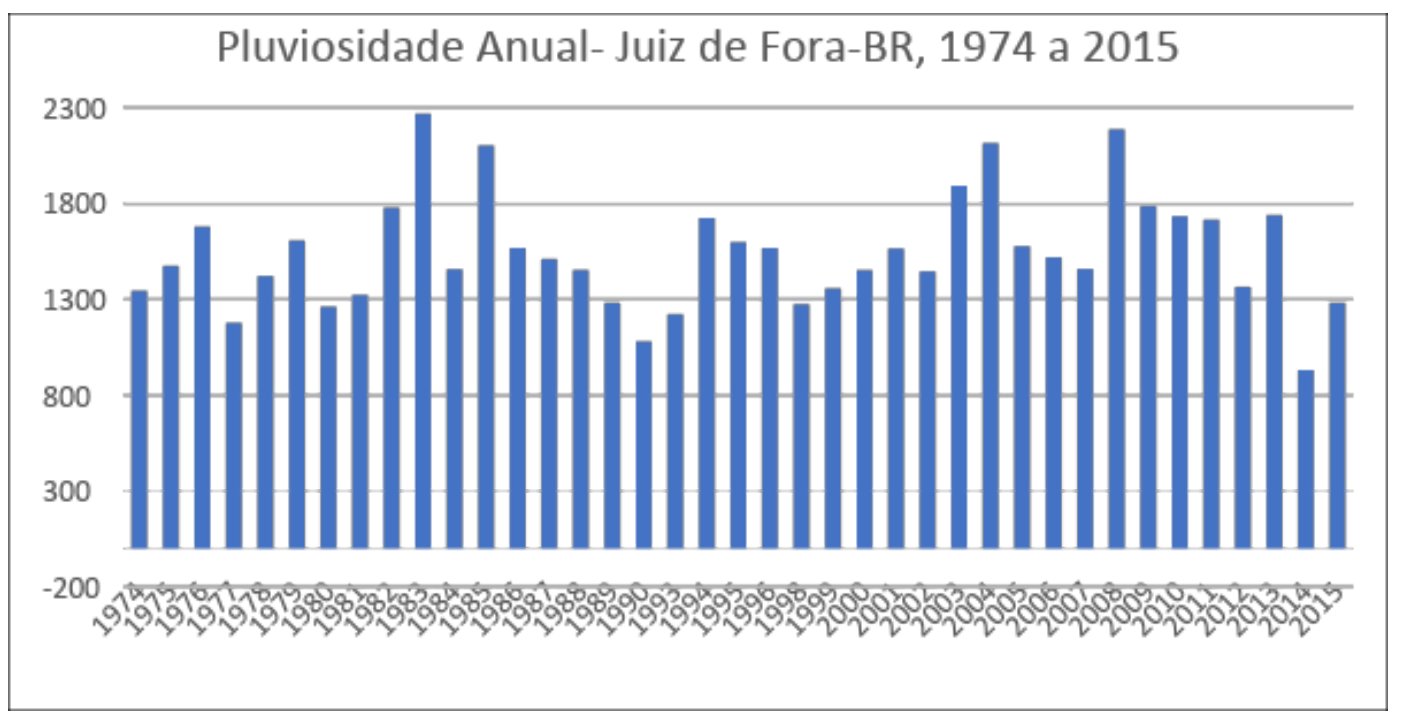

FIGURA 8: Médias móveis e tendência linear do comportamento da precipitação anual na cidade de Juiz de Fora entre 1974 e 2015. Fonte: próprio autor, 2018. 


\section{Metodologia}

Este trabalho é um recorte do Plano Metropolitano de Adaptação às Alterações Climáticas da Área Metropolitana do Porto, no qual foi explorado os dados e informações obtidos em um questionário aplicado aos cidadãos que residem e trabalham na Área Metropolitana do Porto. De forma concomitante, este questionário, após pequenas adaptações de conteúdo e linguagem, foi aplicado também aos residentes da cidade de Juiz de Fora-MG-Brasil, visando obter uma análise integrada e comparativa entre ambos contextos e realidades.

O Plano Metropolitano de Adaptação às Alterações Climáticas da Área Metropolitana do Porto objetiva realizar um diagnóstico estratégico e de uma visão estratégica concretizada em medidas de adaptação. Visando atingir estes objetivos foram sistematizadas e subdivididas nas seguintes etapas: primeiramente, na caracterização do contexto climático atual, posteriormente, a identificação dos cenários climáticos futuros e em terceiro lugar, na identificação dos riscos climáticos futuros.

É na terceira etapa que encontramos o cerne deste estudo, que visou elencar a percepção das vulnerabilidades ambientais, sociais e econômicas, procurando compreender a multiplicidade de expectativas de qualidade de vida, bem-estar e saúde. Para alcançar um conhecimento foram utilizados um conjunto de procedimentos, e dentre eles um inquérito, destinado à população em geral, que visou entender as percepções e práticas diante dos potenciais riscos associados às alterações climáticas e eventos extremos, e possibilizar um debate sobre as ações de mitigação e adaptação necessárias no nível local.

Este inquérito pretendeu identificar os riscos pelos quais a população em geral percebia, como o percebia, quais ações adaptativas da sua área de residência, disponibilidade em participar de ações de adaptação e a preocupação com os riscos. Destinou-se à participação do maior número de pessoas com diversos perfis etários, culturais, sociais e económicos, possibilitou avaliar os vários modos de relacionamento de cada grupo populacional com o clima, com a incerteza associada ao seu carácter e com as perdas e danos de que já foram ou podem vir a ser vítimas.

Os questionários ainda permitirão confrontar a identificação resultante da investigação científica com a avaliação das vivências reais de cada cidadão.

Os questionários cumprem, portanto, diversas funções. Servem para ajudar a elaborar o diagnóstico dos riscos climáticos locais percebidos e mais valorizados pelos indivíduos tanto na sua área de residência como na sua área de trabalho. Ajudam a envolver as pessoas na identificação do(s) problema(s) e a co-responsabilizarem-se nas soluções que vierem a ser encontradas. Preparam os indivíduos para co-criarem com os investigadores, 
com os planeadores e com os decisores as soluções de adaptação mais adequadas no seu contexto geográfico em concreto. E, iniciam e/ou melhoram a literária climatológica" (Plano de Adaptação as Alterações Climática da Área Metropolitana do Porto, 2017).

\section{1- Características Gerais da amostra, Área Metropolitana do Porto:}

O inquérito foi conduzido "online" e divulgado através de e-mails, redes sociais e páginas de internet ${ }^{1}$.

Recorreu-se, portanto, ao procedimento de amostragem não aleatória - amostragem por conveniência -, sendo os entrevistados recrutados em função da sua acessibilidade e desejo de colaboração. Para além disso foi solicitado que as 17 Câmaras Municipais colocassem na sua página uma ligação para o inquérito com o título: "Tem 10 minutos para nos dizer o que mais o preocupa relativamente às Alterações Climáticas?"

Ficou aberto para respostas no período de 01 de Maio de 2017 ate 31 de dezembro de 2017.

A amostra obtida foi de 1488 indivíduos, de um total aproximado de 1.700 .000 residentes (INE, 2011). Correspondendo a aproximadamente $0,087 \%$ da população residente.

\section{2- Características Gerais da amostra, cidade de Juiz de Fora-MG-Brasil}

Os procedimentos metodológicos e a forma de disseminação adotados foram iguais aos utilizados para a $\mathrm{AMP}^{2}$.

No início do questionário foi um texto explicativo, sobre os objetivos do questionário e a que ele serviria. Como segue:

Muitos são os argumentos utilizados para explicar a variabilidade do clima, sejam aqueles que atribuem maior peso às causas antrópicas, ou aqueles que dão mais importância à variabilidade intrínseca ao próprio sistema climático, independentemente deles o que é unânime é que as Alterações Climáticas estão repercutindo cada vez mais em uma sequencia de eventos extremos climáticos, sejam eles ligados à seca ou chuva intensa, maior propagação de doenças

https://docs.google.com/forms/d/e/1FAlpQLSfToklbvN06OASmlj753qRXfmaetiBRKBcAMs_AzM-qxpqCJA/viewform?usp=sf_lin k

2

https://docs.google.com/forms/d/e/1FAIpQLSfS2ERWcMwBqaGMePwkUPd6qRR-KRfvdbze5olshnXiONXrTw/vi ewform
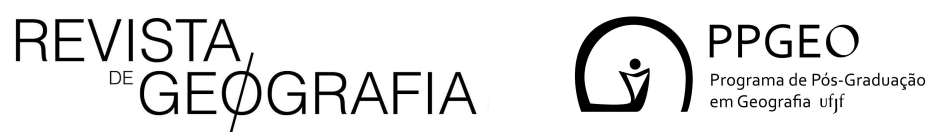
infecciosas, ao extremo calor ou frio, etc.

Para isso, torna-se fundamental planejar ações que permitam prevenir ou mesmo minimizar a repercussão dos eventos associados as alterações climáticas.

Visando isso, está sendo realizado na Área Metropolitana do Porto-Portugal um "Plano Metropolitano de Adaptação às Alterações Climáticas", um dos procedimentos na realização deste plano, consiste no levantamento junto à população sobre questões ligadas às Alterações Climáticas e a percepção da população e dos administradores locais com relação a elas e aos riscos climáticos.

Afim de verificar, comparar e detectar como a mesma metodologia se mostra em localidades com cultura, economia, política, meio, etc. diferentes, optou-se por empregar o mesmo plano para a cidade de Juiz de Fora- MG-Brasil, consistindo numa pesquisa de pós-doutoramento da profa. Cássia de Castro Martins Ferreira junto a Universidade do Porto-Portugal/Universidade Federal de Juiz de Fora.

Uma primeira fase deste plano é a realização de um Inquérito Institucional, consistindo em um questionário que é um elemento importante para a definição no Plano de Adaptação às Alterações Climáticas, das futuras e possíveis ações de adaptação aos riscos climáticos.

A sua opinião é decisiva para instituir critérios e ações visando uma futura cidade mais sustentável, saudável e atenta aos riscos associados às alterações climáticas.

Nesse sentido, agradecemos que preencha este questionário.

Os questionários foram divulgados e começaram a ser respondidos um mês após o início da aplicação na AMP. Ficou aberto para preenchimento online de 01 de junho de 2017 a 31 de agosto de 2017.

A amostra foi de 587 indivíduos, de um total de 563.769 (população residente estimada, 2017). Correspondendo a $0,1 \%$ da população residente.

\section{Resultados e Discussões}

\section{1- Os riscos climáticos identificados pela população}

A amostra total obtida foi de 1488 indivíduos, no qual $69 \%$ foram mulheres e $39 \%$ homens (AMP) e em Juiz de Fora foram um total de 578 indivíduos, com 60,2\% de mulheres e $39,6 \%$ homens e $0,2 \%$ preferiram não dizer. Em ambas as amostras houve maior participação das mulheres.

Houve uma maior participação de indivíduos residentes na AMP na faixa etária dos $31-50$ anos (47\%), seguidos dos de 18-30(29\%) e 51-65 (28\%), e por fim 66-79 anos com $3 \%$. Já para a cidade de Juiz de Fora-Br a maioria dos questionários foram respondidos por indivíduos na faixa etária dos $18-30$ anos $(51,4 \%)$, seguidos dos de $31-50$ anos $(31 \%)$ e 
51-65 anos com 14,9\%, na faixa entre 10 e 17 anos, houve um total de 2,4\% e na de 66 a 79 anos de apenas $0,5 \%$.

Quando analisadas a escolaridade em ambas localidades, prevaleceram aqueles que possuem elevadas habilitações acadêmicas.

A amostra da AMP mostrou uma maior concentração relativa de respostas de residentes nos concelhos de Arouca, Maia, Porto e Vila Nova de Gaia, verificando-se um número reduzido de respostas para os demais municípios. Para a cidade de Juiz de Fora-Br, houve uma grande dispersão de respostas por todas as regiões administrativas da cidade, havendo uma maior concentração nas regiões Centro, São Mateus e São Pedro, locais aonde normalmente os estudantes universitários residem, uma vez que estes compreenderam um total de $33 \%$ da amostra.

\section{Grau de preocupação com os riscos climáticos}

Este item avaliou o grau de preocupação dos residentes da AMP e da cidade de Juiz de Fora com relação a catorze riscos climáticos (Gráfico 7, 8).

Quando analisados os dados da AMP, mais de $90 \%$ dos inquiridos, apontam para uma maior percepção e preocupação dos riscos climáticos, atrelados ao aumento dos períodos de seca severa, ao aumento dos incêndios florestais, à diminuição da qualidade e/ou quantidade de água potável, aumento das cheias e inundações e aumento da erosão costeira. Em Juiz de Fora-Br, os inquiridos não percebem os riscos climáticos elencados nas escalas de preocupado e muito preocupado, para a escala de $90 \%$.

Para a escala dos $80 \%$, a maior parte dos inquiridos, que ficaram preocupados ou muito preocupados indicaram os seguintes riscos para AMP: agravamento das doenças respiratórias, circulatórias e alergológicas, aumento de dias com calor extremo, aumento das precipitações intensas, aumento de doenças contagiosas de clima quente, aumento da velocidade dos ventos, aumento dos dias com frio extremo e aumento dos custos de energia. Nessa escala, para Juiz de Fora são destacados dois riscos, a saber, a diminuição da qualidade/quantidade de água potável e o aumento dos períodos de seca severa.

Percebemos que as vivências locais são importantes na percepção do risco climático, pois em ambas as localidades, foram destacados principalmente os riscos climáticos que a população está vivenciando ou vivenciou em um período recente, como os incêndios florestais, muito divulgado na mídia no verão de 2017, ou mesmo a seca severa no qual a população vem passando neste inverno 2017/2018, em Portugal. Para Juiz de Fora, foi constatado nos últimos 4 anos, dois anos com seca severa, o que levou a uma queda no abastecimento de água potável à população. Logo, deram destaque aos riscos 
que observaram através dos seus sentidos, seja de elementos que presenciaram no seu local de vivência ou das informações provindas principalmente pela mídia e a internet, mas também aquelas divulgadas pelos órgãos públicos, conversas com vizinhos e familiares e o acesso aos resultados de estudos realizados e como processam e criam suas próprias formas de pensar. Segundo Giulio, et al. $(2014$, p.42) "na formação desses julgamentos, pesam suas experiências passadas, as variáveis contextuais, os valores, a confiança nas organizações e instituições envolvidas, as incertezas, entre outros elementos".

$\mathrm{Na}$ escala dos $70 \%$ para a AMP, houve apenas um risco elencado, aumento dos movimentos de vertente. Para Juiz de Fora temos: Aumento dos custos de água potável, aumento dos movimentos de vertente, aumento das cheias e inundações, aumento de doenças contagiosas de clima quente, diminuição da quantidade/qualidade dos alimentos e aumento dos incêndios florestais. Apesar dos vários riscos mencionados já serem uma realidade para a cidade de Juiz de Fora, eles são percebidos por apenas 70 a $79 \%$ dos inquiridos como preocupados ou muito preocupados.

$\mathrm{Na}$ escala dos $60 \%$ para a AMP não houve nenhum risco. Para Juiz de Fora, evidenciaram o aumento nos custos de energia, aumento das precipitações intensas e aumento nos dias de calor extremo. Destacamos que mesmo tendo ocorrido uma nova taxação nas tarifas de energia elétrica, em função dos períodos de seca, não houve uma grande percepção deste fato como um risco climático, assim como um aumento nos dias com calor extremo (Gráfico 5) mostrando um aumento significativo nos dias com temperaturas mais elevadas nas últimas décadas.

$\mathrm{Na}$ escala dos $50 \%$ para a AMP não houve nenhum risco. Para Juiz de Fora destacaram aumento dos dias com frio extremo e da velocidade dos ventos. Com relação ao risco climático de frio extremo, este, no gráfico 4 mostra que nas últimas décadas houve um decréscimo dos dias com baixas temperaturas, o que converge com a percepção dos inquiridos. Quanto aos ventos, por Juiz de Fora estar localizada em uma região de relevo bastante acidentado, caracterizado por Ab' Saber como Mares de Morros, os ventos não são significativos, sendo, portanto, notado pelos inquiridos.

Nas demais escalas não houve resposta quanto a estarem preocupados ou muito preocupados, em nenhuma das duas localidades.

Nos índices de nada preocupado a preocupado para a AMP, houve um número restrito de respostas para todos os riscos. Para Juiz de Fora, tivemos um número mais significativo, chegando a $47 \%, 45 \%$ e $40 \%$ dos inquiridos, quando analisaram o risco de aumento da velocidade dos ventos, de aumento dos dias de frio extremo e de calor extremo respectivamente. 


\section{Importância atribuída às ações para adaptar a área de residência aos riscos climáticos}

Neste item foi solicitado que os participantes classificassem a importância atribuída a cada uma das ações elencadas, para adaptar a área de residência aos riscos climáticos (Gráficos 7 e 8).

De acordo com os resultados obtidos, verificamos que para todas as ações elencadas, na AMP houve maior preocupação com relação as ações e a possível minimização dos riscos climáticos. Levando em consideração os dois níveis mais elevados (muito importante e extremamente importante) na AMP, na escala dos 90\%, foram destacadas as ações: aumento do uso de energia renováveis, dinamização de ações de educação ambiental e aumento de espaços verdes. Para a cidade de Juiz de Fora, não houve nenhuma ação destacada.

$\mathrm{Na}$ escala dos $80 \%$, para a AMP, foram assinalados: aumento/melhoria dos transportes públicos, aumento no número de veículos elétricos, criação de novos regulamentos construtivos promotores de arquitetura bioclimática, criação de um mapeamento detalhado dos riscos climáticos, aumento/melhoria dos espaços públicos e aumento/melhoria da rede pedonal e de ciclovias. Para Juiz de Fora, foram destacadas: aumento do uso de energia renovável, aumento/melhoria das áreas verdes, dinamização de ações de educação ambiental e mapeamento detalhado dos riscos climáticos.

Verificamos que parte das ações elencadas em ambas localidades estão diretamente relacionadas à própria divulgação da mídia no sentido de melhoria da qualidade de vida e da minimização dos impactos advindos das alterações climáticas. Repercutindo na visão dos inquiridos, de quais ações seriam mais adequadas na minimização do risco climático. 


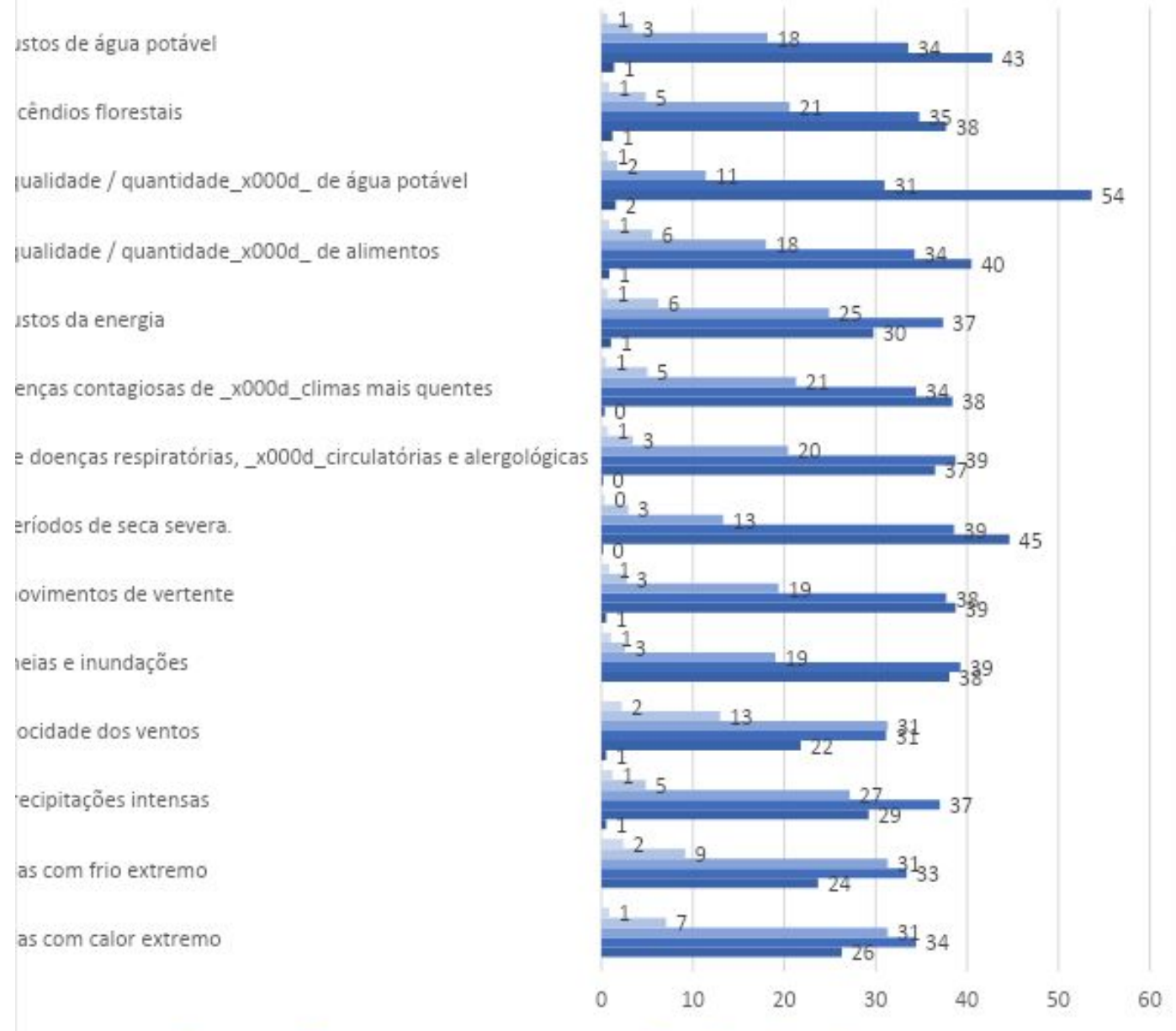

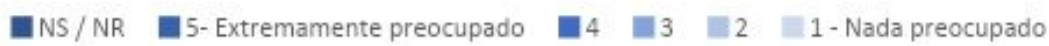

FIGURA 9: Grau de preocupação com os riscos climáticos - Juiz de Fora-MG-Brasil. Fonte próprio autor, 2018. 
Aumento dos incêndios florestais

Diminuição da qualidade / quantidade_x000d_de água potável

Diminuição da qualidade / quantidade_x000d_de alimentos

Aumento dos custos da energia

Aumento de doenças contagiosas de _x000d_climas mais quentes

Agravamento de doenças respiratórias, _x000d_circulatórias e alergológicas

Aumento dos períodos de seca severa.

Aumento dos movimentos de vertente

Aumento das cheias e inundações

Aumento dos ventos velozes

Aumento das precipitações intensas

Aumento dos dias com frio extremo

Aumento dos dias com calor extremo

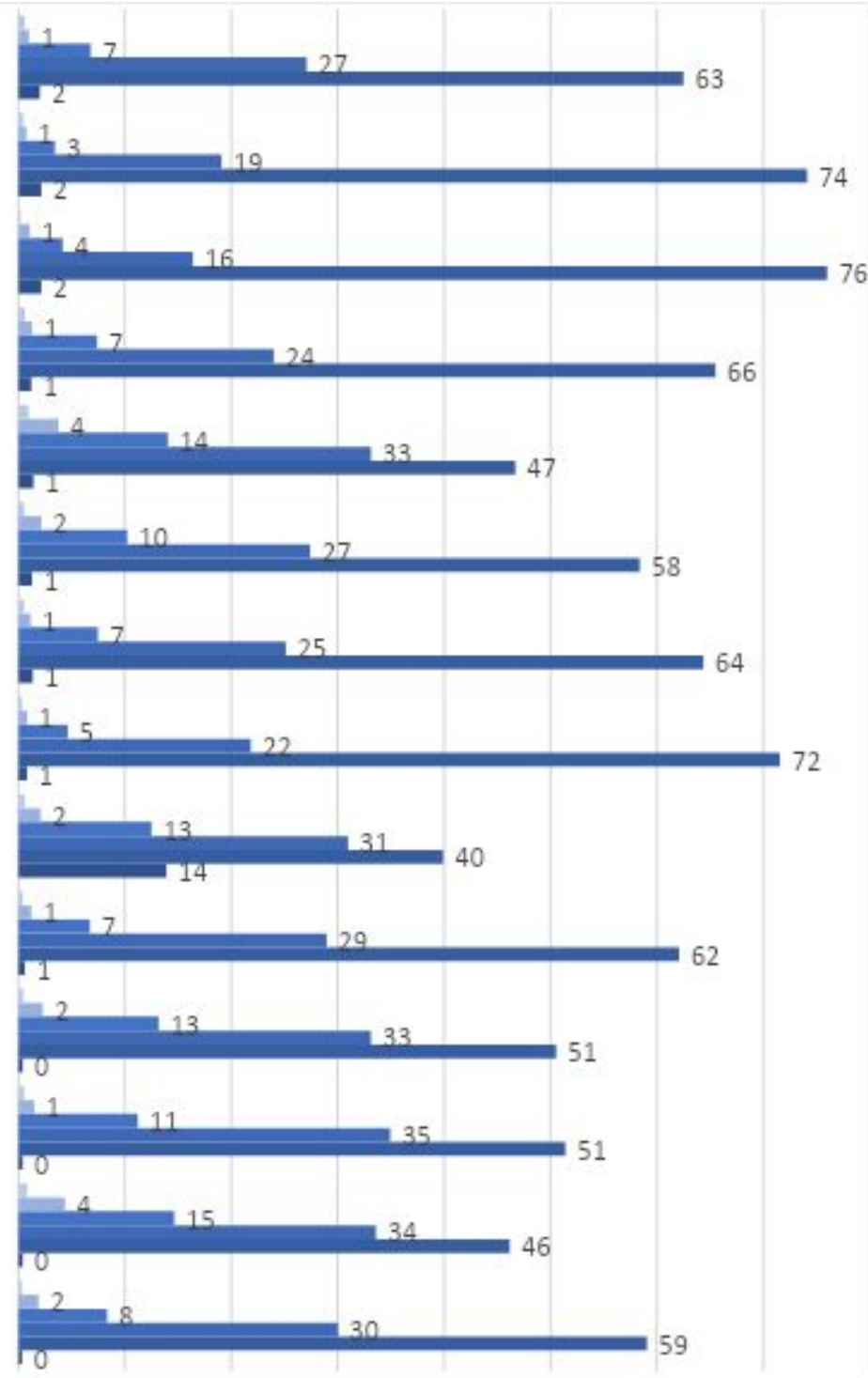

NS / NR 5- Muito preocupado $3^{20}-3^{30}-2_{1}^{40}-\mathrm{Nada}^{50}$ preocupado

FIGURA 10: Grau de preocupação com os riscos climáticos, AMP-Portugal. Fonte: PLANO METROPOLITANO DE ADAPTAÇÃO ÀS ALTERAÇÕES CLIMÁTICAS NA ÁREA METROPOLITANA DO PORTO, 2017.

$\mathrm{Na}$ escala dos $70 \%$ para a AMP, destacaram apenas a ação: criação de painéis informativos do conforto térmico e da qualidade do ar. Já em Juiz de Fora, foram assinaladas as ações: melhoria da quantidade/qualidade da água, aumento da rede pedonal e de ciclovias, aumento e melhoria dos espaços públicos, criação de novos regulamentos construtivos promotores de arquitetura bioclimática e criação de painéis informativos do conforto térmico e da qualidade do ar. É importante destacar que a maior parte das ações destacadas são ausentes e quando presentes estão e são em pequena quantidade e qualidade, e portanto, teriam que ser quase na sua totalidade implantadas na cidade de Juiz 
de Fora, mesmo assim, os inquiridos apresentaram boa percepção no que tange à melhoria, qualidade e mesmo necessidade de implantação.

Quando analisada a escala dos $60 \%$, para a AMP, apenas uma ação foi assinalada: desentubamento dos cursos d'água. Já para Juiz de Fora, foram assinalados: aumento e melhoria dos transportes públicos, aumento no número de veículos elétricos, aumento do uso do biocombustível e desentubamento dos cursos d'água. Nesta escala, para Juiz de Fora são assinalados todos os itens referentes ao transporte, dando talvez uma menor valorização, por não terem visto a relação dessas ações com os riscos climáticos.

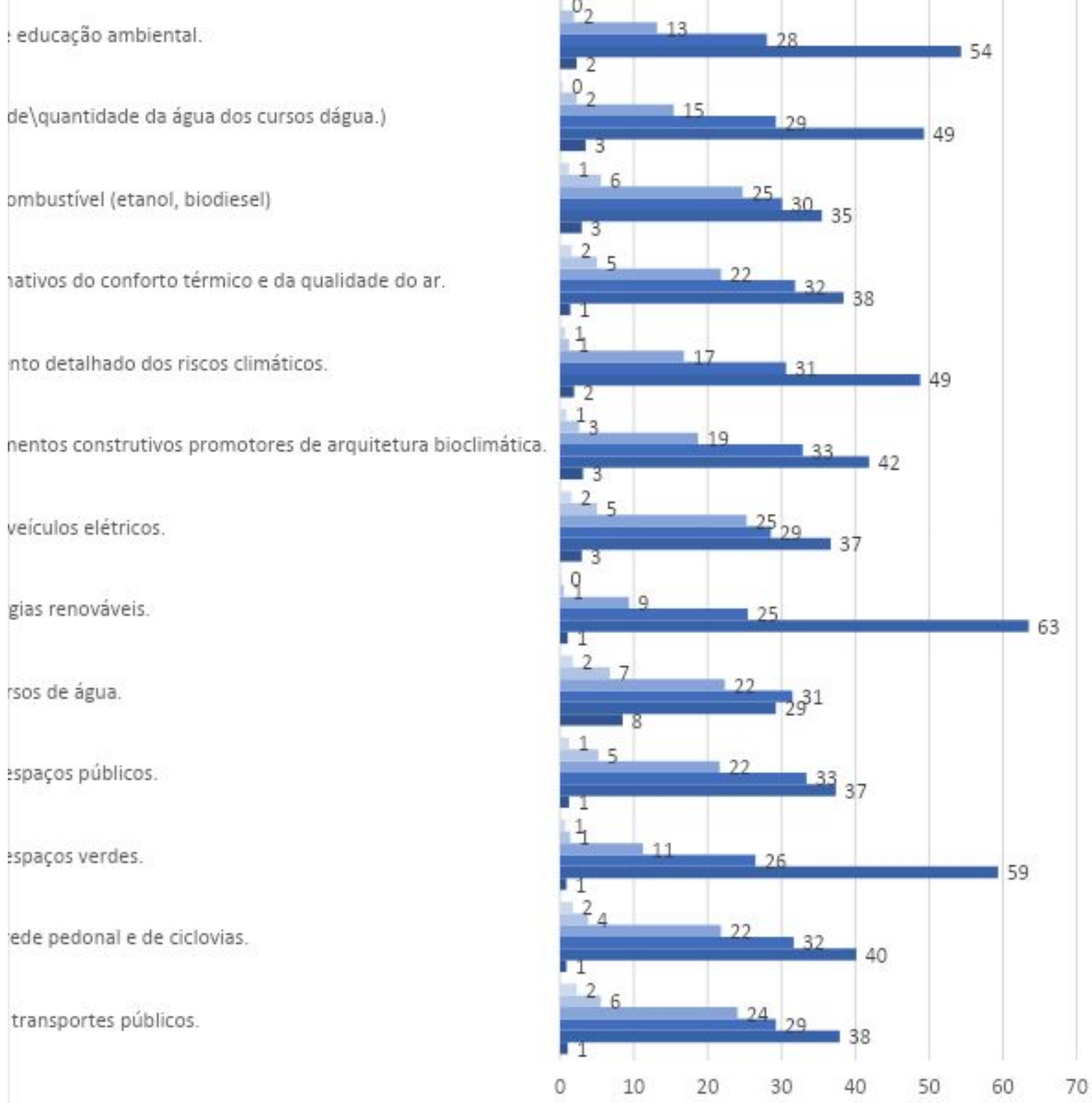

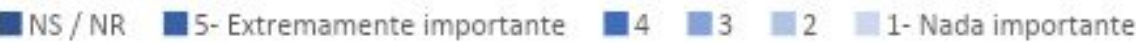


FIGURA 11: Importância atribuída às ações para adaptar a área de residência aos riscos climáticos- Juiz de Fora-MG-Brasil. Fonte próprio autor, 2018.

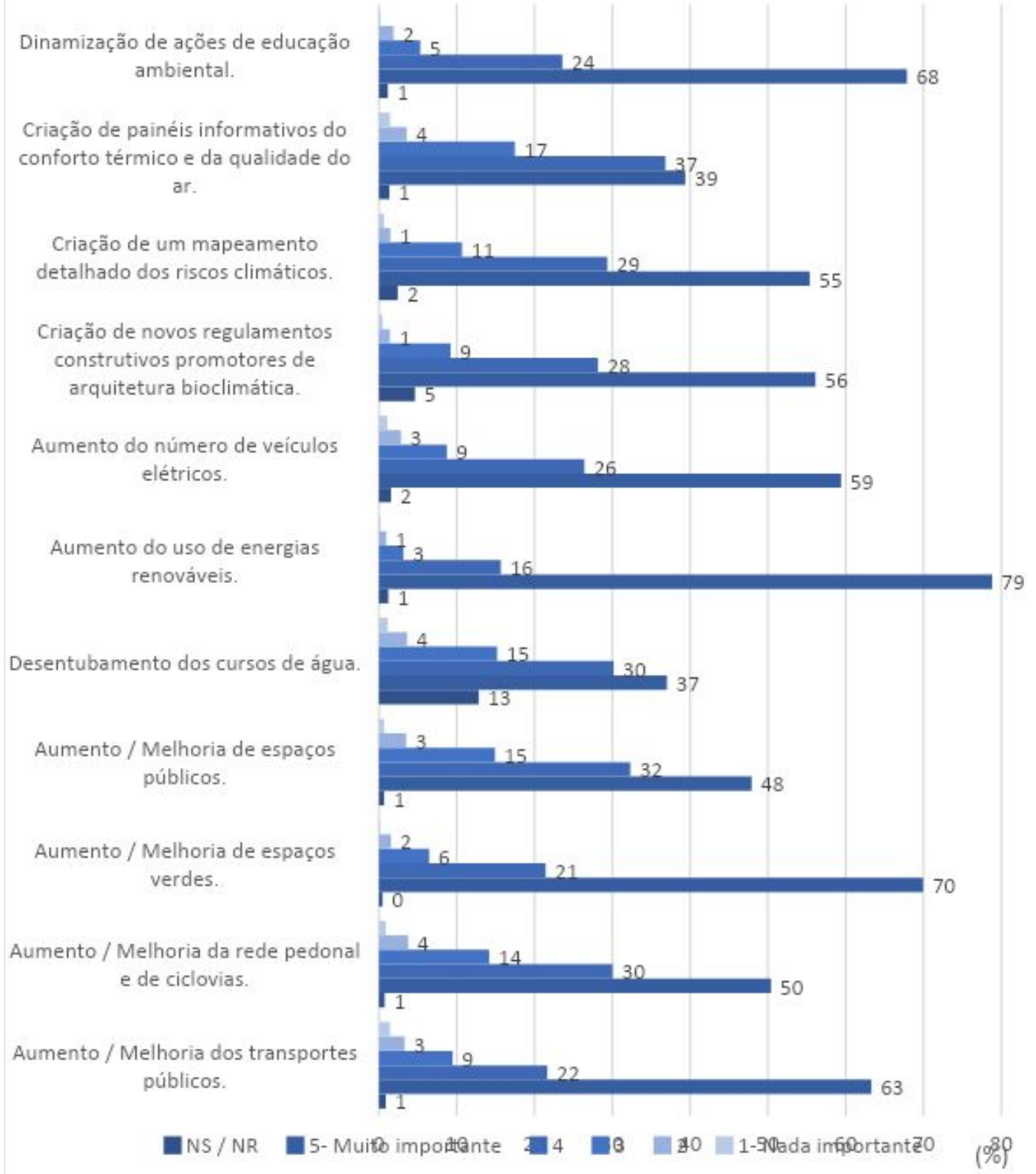

FIGURA 12: Importância atribuída às ações para adaptar a área de residência aos riscos climáticosAMP-Portugal. Fonte: PLANO METROPOLITANO DE ADAPTAÇÃO ÀS ALTERAÇÕES CLIMÁTICAS NA ÁREA METROPOLITANA DO PORTO, 2017.

\section{Disponibilidade para participar em ações de adaptação aos riscos climáticos}


Nesta questão os inquiridos foram convidados a refletir se participariam em alguma ação para adaptar seus concidadãos aos riscos climáticos. Na AMP e em Juiz de Fora, $64 \%, 40 \%$ afirmaram sua participação, $11 \%$, 21\% negaram e $25 \%$, 39\% não respondeu ou não emitiu opinião, respectivamente. Verifica-se aqui uma queda na adesão, seja pela atribuição ao poder público na tomada de decisões e ações, ou mesmo por não se verem como cidadãos capazes de desempenhar atividades e ações que poderiam contribuir com a minimização dos riscos climáticos.

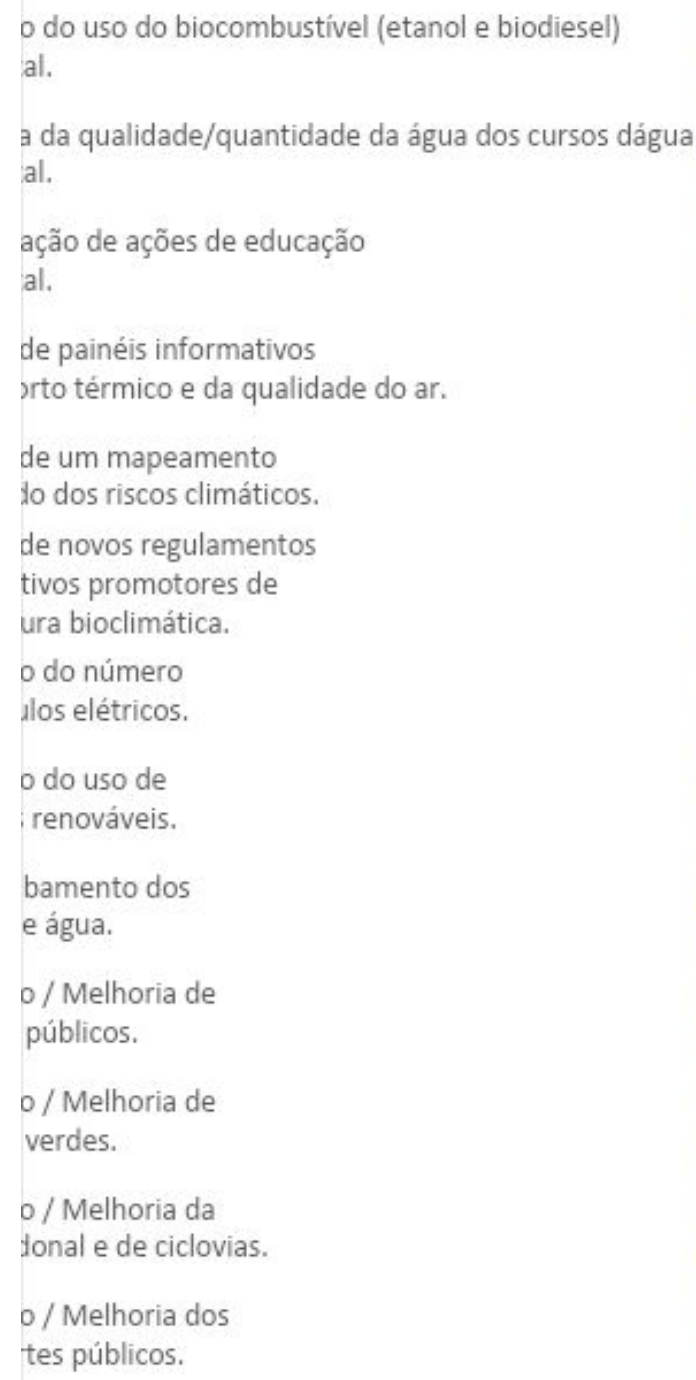

\section{.}
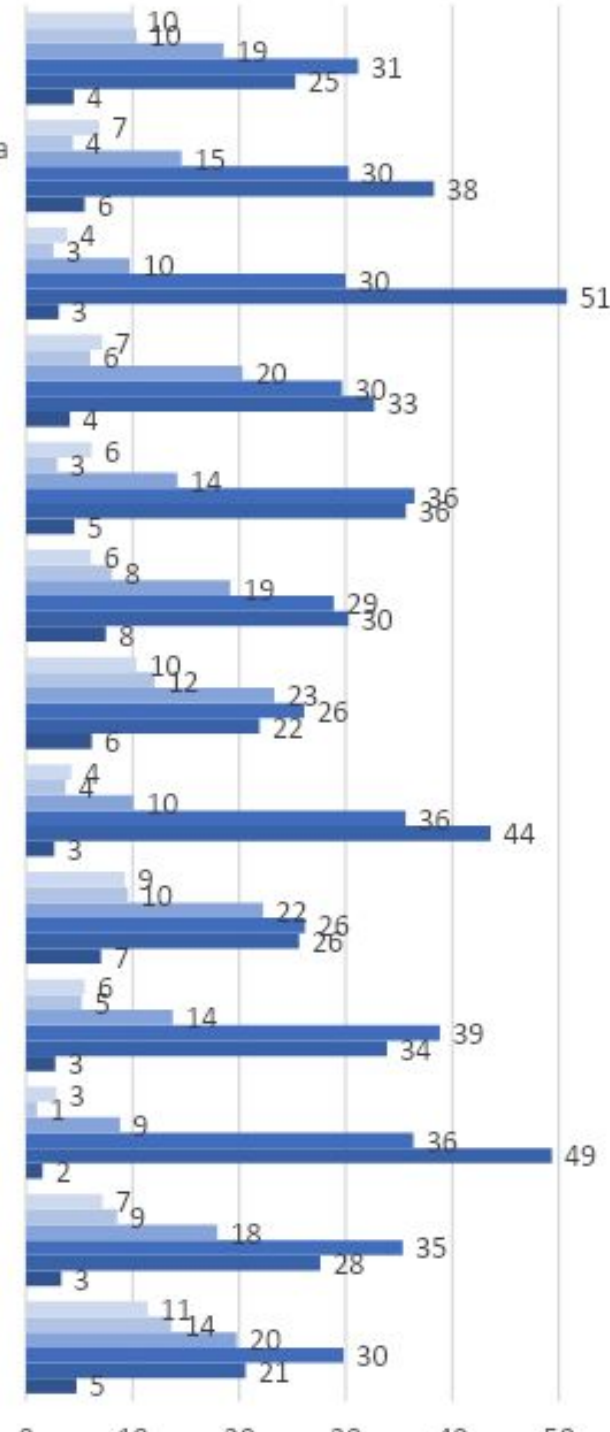

$\begin{array}{lllllll}0 & 10 & 20 & 30 & 40 & 50 & 60\end{array}$ 
FIGURA 13: Disponibilidade para participar nas diferentes ações de adaptação aos riscos climáticos na área de residência (\%) - Juiz de Fora-MG-Brasil. Fonte próprio autor, 2018.

Para aqueles que responderam afirmativamente, em uma segunda questão, foi solicitado que classificassem e demarcassem quais ações estaria disposto a participar (Gráficos 9 e 10).

Em ambas as localidades detectou-se que os inquiridos se colocaram em ações que tinham maior capacidade e estavam mais próximas do seu cotidiano e vivência, tais como: aumento do uso de energias renováveis e com o aumento e/ou melhoria de espaços verdes, a dinamização de ações de educação ambiental, talvez pela maior facilidade em atuar nessas ações. A participação em ações de desentubamento de cursos de água é aquela que recebe menos suporte por parte dos respondentes.

Destacamos que as percepções de risco climático dos moradores das duas localidades analisadas, mostrou que as percepções dos indivíduos ainda estão atreladas e são construídas num processo de experiências do seu espaço vivido, da associação com eventos divulgados em outras localidades pela mídia, internet, etc e pelo grau de afetividade com o lugar e com os atingidos, formando um conceito e um conjunto de informações que o levam a dar maior ou menor importância aos riscos climáticos. Esta concepção também é trabalhada por Weber (2010) e Giulio et al. (2014).

\section{Conclusões}

Os riscos climáticos são um conceito aparentemente dominado por todos os que responderam ao inquérito. Pois, a percepção de risco climático pelos inquiridos, nos remete a concepção de que estes foram definidos em função da vivência de cada um e do que já obtiveram de informação (mídia, internet, amigos, familiares) ou mesmo daqueles que já sofreram com alguma situação de risco.

Em ambas as localidades, a preocupação com o risco climático é elevada, pelo menos $60 \%$ dos inquiridos assinalaram que estão muito ou extremamente preocupados com os riscos climáticos.

Na AMP houve maior preocupação, seja por terem maior acesso a informação, e os riscos climáticos em Portugal estão melhor detalhados, estudados e divulgados, o que não 
ocorre para o Brasil, no qual os riscos climáticos ainda são tratados de forma genérica, em um país com dimensões territoriais significativas, que não terá as mesmas respostas em todo o seu território, mostrando uma certa desinformação quanto aos reais impactos das alterações climáticas e os consequentes riscos, esse fato pode ter influenciado nas respostas dos inquiridos. 


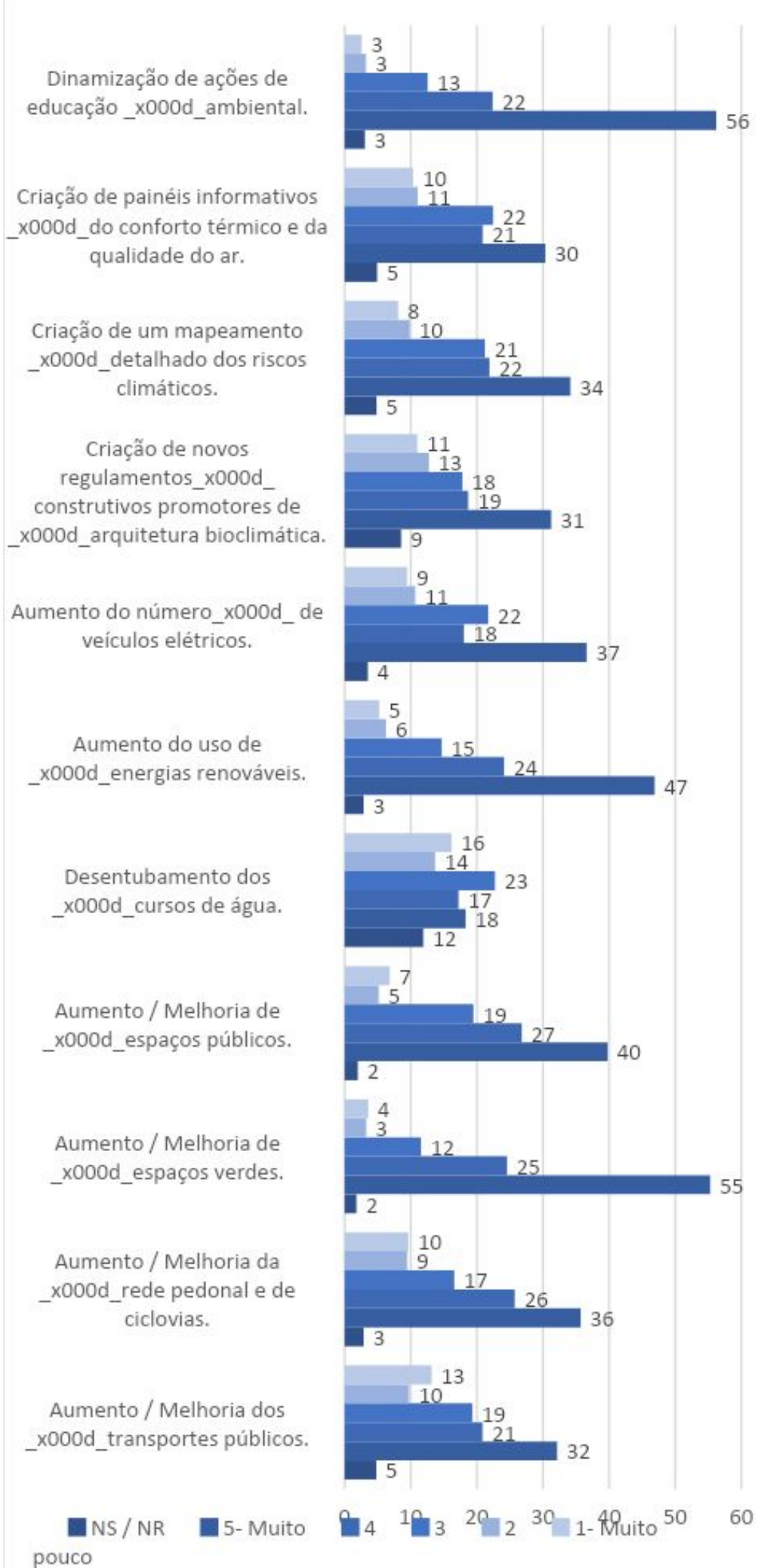
Criação de painéis informativos _x000d_do conforto térmico e da qualidade do ar.

Criação de um mapeamento

Criação de novos

regulamentos_x000d_ construtivos promotores de _x000d_arquitetura bioclimática.
Aumento do número_x000d_de veículos elétricos.

\begin{abstract}
Aumento do uso de x000d_energias renováveis.
\end{abstract}

Desentubamento dos
_xo00d_cursos de água.
Aumento / Melhoria de
_xo00d_espaços públicos.
Aumento / Melhoria de
_xoo0d_espaços verdes.
Aumento / Melhoria da
x000d_rede pedonal e de
ciclovias.
Aumento / Melhoria dos
xoood transportes públicos.
pouco

NS / NR 5uito

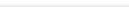

FIGURA 14: Disponibilidade para participar nas diferentes ações de adaptação aos riscos climáticos na área de residência (\%). AMP-Portugal. Fonte: PLANO METROPOLITANO DE ADAPTAÇÃO ÀS ALTERAÇÕES CLIMÁTICAS NA ÁREA METROPOLITANA DO PORTO, 2017. 


\section{REFEREÊNCIAS BIBLIOGRÁFICAS}

ADGER, W. N.; HUQ, S.; BROWN, K.; CONWAY, D.; HULME, M. Adaptation to climate change in the developing world. Progress in Development Studies. v. 3, n. 3, p. 179-195, 2003.

AMORIM, M.C.C.T.; SANT'ANNA NETO, J.L.; DUBREUIL, V. Estrutura térmica identificada por transectos móveis e canal termal do landsat 7 em cidade tropical. Revista de Geografia Norte Grande, Santiago-Chile, v.43, p. 65-80, 2009.

AMP - Área Metropolitana do Porto, 2017. Disponível em: <http://portal.amp.pt/pt/4/stats/demografia/\#FOCO 4>. Acesso em: 10 jan. 2018.

ASIAN DEVELOPMENT BANK. Addressing climate change risks, disasters, and adaptation in the People's Republic of China. Mandaluyong City, Philippines: Asian Development Bank, 2015.

BANCO MUNDIAL. Building Resilience: Integrating Climate and Disaster Risk into Development. Washington DC: Banco Mundial, 2013.

BARBI, F.; FERREIRA, L. C. F. Climate Change in Brazilian Cities: Policy Strategies and Responses to Global Warming. International Journal of Environmental Science and Development. v. 4, n. 1, p. $49-51,2013$.

BARCELONA. Ajuntament de Barcelona: Environment Report. Barcelona, a city committed to the environment: Resilience and climate change adaptation. Barcelona, 2013.

BOSTON. Metropolitan Area Planning Council. Metro Boston Regional Climate Change Adaptation: Strategy Report Funding provided by the Federal Sustainable Communities Program and the Barr Foundation. Boston: Tellus Institute, 2014.

CASTRO, S. D. A. Riesgos y peligros: una visión desde lá Geografía. Scripta Nova: Revista Electrónica de Geografía y Ciencias Sociales. Barcelona, v.4, n.55-78, 2000.

DI GIULIO, G. M. Risco, ambiente e saúde: um debate sobre comunicação e governança do risco em áreas contaminadas. São Paulo: Annablume, 2012.

DI GIULIO, G. M.; FIGUEIREDO, B. R.; FERREIRA, L. C.; ANJOS, J. A. S. Experiências brasileiras e o debate sobre comunicação e governança do risco em áreas contaminadas por chumbo. Ciência e Saúde Coletiva (Impresso), v. 17, p. 337-349. 2012.

DI GIULIO, G.M.; SERRAO-NEUMANN, S.; VIGLIO, J.E.; FERREIRA, L.C.; CHOY, D.L. Propostas metodológicas em pesquisas sobre o risco e adaptação: experiências no Brasil e na Austrália. Ambiente \& Sociedade. São Paulo. v. XVII, n. 4, p. 35-54, out.-dez. 2014.

DURBAN. Environmental planning e climate protection department. Durban's Municipal Climate Protecon Programme: Climate change planning for resilient city, 2010/2011. Durban: Triple green paper, 2012.

ELIASSON, I. The use of climate knowledge in urban planning. Landscape and Urban Planning, v.48, n.1-2, p. 31-44, 2000.

EUROPEAN UNION. European Environment Agency. An indicator-based report; Urban adaptation to climate change in Europe 2016. Luxembourg: Publications Office of the European Union, 2017b.

EUROPEAN UNION. European Environment Agency. Climate change, impacts and vulnerability in Europe 2016. Luxembourg: Publications Office of the European Union, 2017a.

EUROPEAN UNION. European Environment Agency. Urban adaptation to climate change in Europe 2016: Transforming cities in a changing climate. Luxembourg: Publications Office of the European Union, 2016.

FIALHO, E. S. Ilha de calor: reflexões acerca de um conceito. ACTA Geográfica, Boa Vista, Ed. Esp. Climatologia Geográfica, p.61-76, 2012. 
FREITAS, C. M. A contribuição dos estudos de percepção de riscos na avaliação e no gerenciamento de riscos relacionados aos resíduos perigosos. In: SISINNO, C. L. S.; OLIVEIRA, R. M. (Orgs.). Resíduos sólidos, ambiente e saúde: uma visão multidisciplinar. Rio de Janeiro: Fiocruz., 2000, p.111-128.

FRIEND, R.; MOENCH, M. What is the purpose of urban climate resilience? Implications for addressing poverty and vulnerability. Urban Climate. v. 6, n. 1, p. 98-113, 2013.

FUNTOWICZ, S.; RAVETZ, J.. Ciência pós-normal e comunidades ampliadas de pares face aos desafios ambientais. Hist. cienc. saúde-Manguinhos, Rio de Janeiro, v. 4, n. 2, p. 219-230.1997.

HARDOY, D. J.; PANDIELLA, G. Urban poverty and vulnerability to climate change in Latin America. Environment and Urbanization. v. 21, n. 1, p. 203-224, 2009.

HELSINKI. Helsinki Region Environmental Services Authority.Helsinki Metropolitan Area Climate Change Adaptation Strategy. Helsinki: HSY publications, 2012.

HOPPE, T., VAN DEN BERG, M. M., \& COENEN, F. H. Reflections on the uptake of climate change policies by local governments: facing the challenges of mitigation and adaptation. Energy, Sustainability and Society, v.4, n.1, p. 8-16. 2014.

IBGE - Instituto Brasileiro de Geografia e Estatística, Censo 2010, estimativa 2017. Disponível em: https://cidades.ibge.gov.br/brasil/mg/juiz-de-fora/panorama. Acesso em: 12 jan. 2018.

INE - Instituto Nacional de Estatística - Statistics Portugal, Censo 2011. Disponível em: < https://www.ine.pt/xportal/xmain?xpid=INE\&xpgid=ine base dados\&contexto=bd\&selTab=tab2>.

Acesso em 12 jan. 2018.

IPCC - INTERGOVERNMENTAL PANEL ON CLIMATE CHANGE. Annex II: glossary. In: THE CORE WRITING TEAM; PACHAURI, R. K.; MEYER, L. A. (Eds.). Climate Change 2014: synthesis report. Contribution of Working Groups I, II and III to the Fifth Assessment Report of the Intergovernmental Panel on Climate Change IPCC. Geneva: IPCC, 2014. Disponível em: <http://goo.gl/b7AISP>.

KLUG, L.; MARENGO, J.A.; LUEDEMANN, G. Mudanças climáticas e os desafios brasileiros para implementação da nova agenda urbana. P. 303-323. In: COSTA, M.A. (Org.). O Estatuto da Cidade e a Habitat III: um balanço de quinze anos da política urbana no Brasil e a Nova Agenda Urbana. Brasília: Ipea, 2016.

KOWARICK, L. Viver em risco: sobre a vulnerabilidade no Brasil urbano. Novos Estudos. v. 63, n. 1, p. 9-29, 2002.

MANCHESTER. Manchester city council's climate change belivery plan 2010-2020: The council's contribution to Manchester - A certain future. Manchester: Manchester.gov.uk, 2011.

MCCARNEY, P. L.. City indicators on climate change: implications for policy leverage and governance. In: World Bank's 5th Urban Research Symposium Cities and Climate Change: Responding to an Urgent Agenda. Anais... Marseille, 2009.

MONTEIRO, A. Riscos climáticos: hazards, áleas, episódios extremos. In: AMORIM, M.; SANTANANNA NETO, J.L. (Org.). Climatologia urbana e regional: Questões teóricas e estudos de caso. São Paulo: Editora Outras Expressões, 2013, p. 143-172.

MONTEIRO, A., CARVALHO, V., Clima e Planejamento Regional. In: AMORIM, M.; SANTANANNA NETO, J.L. (Org.). Climatologia urbana e regional: Questões teóricas e estudos de caso. São Paulo: Editora Outras Expressões, 2013, p. 93-116.

MONTEIRO, A., VELHO, S., ALMEIDA, M., FONSECA, L., A (in)eficácia das políticas europeias e nacionais para prevenir os riscos causados pelas manifestações de mudança climática nos espaços urbanos. Revista da Faculdade de Letras - Geografia - Universidade do Porto Série 3, v 1, p. 45-58. 2012.

NEW YORK. The City of New York. A stronger, more resilient New York. New York: Mayor MMBloomberg, 2013.

OKE, T. R. Methods in urban climatology. App. Climatol. 14: 19-29, 1984. 
OKE, T.R. Boundary Layer Climates. 2. ed. New York: Routledgep, 1987.

ONU-HABITAT. Global report on human settlements 2011: Cities and Climate Change. London Washington, DC: United Nations Human Settlements Programme, 2011.

PARIS. Direction des Espaces Verts et de l'Environnement, Agence d'Écologie Urbaine. Paris Adaptation strategy: towards a more resilient city. Paris: Agence 9, 2015.

PORTO. Plano Metropolitano de adaptação as Alterações Climáticas da Área Metropolitana do

Porto (em elaboração). METROCLIMA - Adaptação às alterações climáticas na área metropolitana do Porto (AMP): conhecer, planear, comunicar, antecipar. poseur-02-1708-fc-000010, Porto-Portugal, 2017.

PORTUGAL. Agência Portuguesa do Ambiente - APA. ClimAdaPT.Local: estratégias municipais de adaptação as alterações climáticas. Portugal: APA, 2015.

RAMIRES, J.Z.S. Políticas públicas, mudanças climáticas e riscos em São Paulo. 2015, 243f. Tese (Doutorado em Geografia Humana) - Programa de Pós-graduação em Geografia Humana, Universidade de São Paulo - USP, São Paulo, 2015.

RENN, Ortwin. Risk governance: coping with uncertainty in a complex world. London: Earthscan. 2008.

REVI, A. et al. Urban areas. In: FIELD, C. B. et al. (Eds.). Climate Change 2014: impacts, adaptation, and vulnerability. Part A: global and sectoral aspects. Contribution of Working Group II to the Fifth Assessment Report of the Intergovernmental Panel on Climate Change. Cambridge; New York: Cambridge University Press, 2014.

RIO DE JANEIRO. Secretaria Municipal de Meio Ambiente; Gerência de Mudanças Climáticas e Desenvolvimento Sustentável; Centro Clima/COPPE/UFRJ. Plano de adaptação da cidade do Rio de Janeiro as mudanças climáticas. Rio de Janeiro, 2017.

SATHLER, D. Repercussões locais das mudanças climáticas globais: urbanização, governança e participação comunitária. Caminhos de geografia, Uberlândia. V.15, n.51, p. 01-19, set/2014.

SOUSA, F.A.S.; MORAIS, H.F.; SILVA, P.R. Influência da Urbanização no clima da cidade de Campina Grande-PB. Revista Brasileira de Geografia Física, Recife, v. 01, p. 134-145, 2011.

VANVOUVER-EUA. Greenest city 2020: climate adaptation. Climate change adaptation strategy: city os Vancouver. Vancouver: City of Vancouver, 2013.

VEYRET, Y. Os Riscos: o homem como agressor e vítima do meio ambiente. Editora Contexto, 2007.

WEBER, Elke U. What shape perceptions of climate change? Wires Climate Change, v. 1, p. 332-342. 2010.

WHILE, A.; WHITEHEAD, M. Cities, Urbanization and Climate Change. Urban Studies. v. 50, n. 7, p. 1325-1331, 2013. 